\title{
Sea salt aerosol production via sublimating wind-blown saline snow particles over sea ice: parameterizations and relevant microphysical mechanisms
}

\author{
Xin Yang ${ }^{1}$, Markus M. Frey ${ }^{1}$, Rachael H. Rhodes ${ }^{2,3}$, Sarah J. Norris ${ }^{4}$, Ian M. Brooks ${ }^{4}$, Philip S. Anderson ${ }^{5}$, \\ Kouichi Nishimura $^{6}$, Anna E. Jones ${ }^{1}$, and Eric W. Wolff ${ }^{2}$ \\ ${ }^{1}$ British Antarctic Survey, Natural Environment Research Council, Cambridge, UK \\ ${ }^{2}$ Department of Earth Sciences, University of Cambridge, Cambridge, UK \\ ${ }^{3}$ Department of Geography and Environmental Sciences, Northumbria University, Newcastle upon Tyne, UK \\ ${ }^{4}$ School of Earth and Environment, University of Leeds, Leeds, UK \\ ${ }^{5}$ Scottish Association for Marine Science, Oban, Argyll, Scotland, UK \\ ${ }^{6}$ Graduate School of Environmental Studies, Nagoya University, Nagoya, Japan
}

Correspondence: Xin Yang (xinyang55@bas.ac.uk)

Received: 10 October 2018 - Discussion started: 9 November 2018

Revised: 23 April 2019 - Accepted: 1 May 2019 - Published: 2 July 2019

\begin{abstract}
Blowing snow over sea ice has been proposed as a significant source of sea salt aerosol (SSA) (Yang et al., 2008). In this study, using snow salinity data and blowing snow and aerosol particle measurements collected in the Weddell Sea sea ice zone (SIZ) during a winter cruise, we perform a comprehensive model-data comparison with the aim of validating proposed parameterizations. Additionally, we investigate possible physical mechanisms involved in SSA production from blowing snow. A global chemical transport model, p-TOMCAT, is used to examine the model sensitivity to key parameters involved, namely blowing-snow size distribution, snow salinity, sublimation function, surface wind speed, relative humidity, air temperature and ratio of SSA formed per snow particle. As proposed in the parameterizations of Yang et al. (2008), the SSA mass flux is proportional to the bulk sublimation flux of blowing snow and snow salinity. To convert the bulk sublimation flux to SSA size distribution requires (1) sublimation function for snow particles, (2) blowing-snow size distribution, (3) snow salinity and (4) ratio of SSA formed per snow particle.

The optimum model-cruise aerosol data agreement (in diameter range of $0.4-12 \mu \mathrm{m}$ ) indicates two possible microphysical processes that could be associated with SSA production from blowing snow. The first one assumes that one SSA is formed per snow particle after sublimation, and snow particle sublimation is controlled by the curvature effect or
\end{abstract}

the so-called "air ventilation" effect. The second mechanism allows multiple SSAs to form per snow particle and assumes snow particle sublimation is controlled by the moisture gradient between the surface of the particle and the ambient air (moisture diffusion effect). With this latter mechanism the model reproduces the observations assuming that one snow particle produces $\sim 10$ SSA during the sublimation process. Although both mechanisms generate very consistent results with respect to observed aerosol number densities, they correspond to completely different microphysical processes and show quite different SSA size spectra, mainly in ultra-fine and coarse size modes. However, due to the lack of relevant data, we could not, so far, conclude confidently which one is more realistic, highlighting the necessity of further investigation.

\section{Introduction}

Over most of the Earth, primary sea salt aerosol (SSA) derives from wave breaking and bubble bursting at the openocean surface (e.g. de Leeuw et al., 2011). SSA is relevant to radiative forcing of climate because it can efficiently scatter solar radiation (O'Dowd et al., 1997; Murphy et al., 1998; Quinn et al., 2002). Moreover, SSA can serve as cloud condensation nuclei (CCN) (e.g. O'Dowd and Smith, 1993; 
O’Dowd et al., 1997, 1999) and even ice-nucleating particles (INPs) (Wise et al., 2012; DeMott et al., 2016) that influence global climate.

Observations of sulfate depletion relative to sodium in Antarctic aerosol and snow samples first argued for a sea ice source of SSA (Wagenbach et al., 1998; Rankin and Wolff, 2003; Jourdain et al., 2008; Legrand et al., 2017). The depletion of sulfate is due to the effect of mirabilite $\left(\mathrm{Na}_{2} \mathrm{SO}_{4} \cdot 10 \mathrm{H}_{2} \mathrm{O}\right)$ precipitation from brine on sea ice when the temperature drops below $-6.4{ }^{\circ} \mathrm{C}$ (Butler et al., 2016), a fractionation not plausible for sea spray particles generated directly from the open ocean. Thus, it allows a new interpretation of the sodium recorded in ice cores, as the open-ocean sea spray is no longer the sole source for salts in snow and ice cores (e.g. Rankin et al., 2002, 2004). Moreover, this finding raises the possibility of using sea salt or sodium recorded in ice cores as a potential sea ice extent proxy for past climates (Wolff et al., 2003; Abram et al. 2013; Severi et al., 2017).

Saline crystals on sea ice, such as frost flowers (FFs) (e.g. Rankin et al., 2000, 2002; Kaleschke et al., 2004; Xu et al., 2016) with relatively high salinity and blowing snow (Yang et al., 2008) with relatively low salinity, were both suggested as potential sources of SSA. Evidence from laboratory chambers (Roscoe et al., 2011; Yang et al., 2017) and field measurements (Obbard et al., 2009; Hara et al., 2017) indicate that FFs are unlikely to be a major direct source. Global models with blowing snow as a SSA source can successfully reproduce winter SSA peaks at high latitudes (Levine et al., 2014; Huang and Jaeglé, 2017; Rhodes et al., 2017). In addition, chemistry transport model studies demonstrate that when this sea-ice-sourced SSA is treated as a source of bromine to the boundary layer, the polar springtime bromine explosion events as well as the associated ozone depletion events can be largely reproduced (Yang et al., 2010; Theys et al., 2011; Legrand et al., 2016; Zhao et al., 2016, 2017; Choi et al., 2018). However, the SSA production parameterizations implemented in models have not been fully validated against field data, and the possible physical mechanisms involved in the SSA formation are not completely clear.

In this study, based on a comprehensive set of measurements for both blowing-snow particles and aerosol particles (Frey et al., 2019), made during a winter cruise on board the icebreaker RV Polarstern within the Weddell Sea sea ice zone (SIZ) in June-August 2013, we could, for the first time, test and validate model parameterizations of SSA production and investigate the model sensitivity to relevant parameters. A brief description of the cruise measurements is given in Sect. 2. Parameterization and model experiments are detailed in Sect. 3. Results of the model-data comparison are given in Sect. 4. Relevant mechanisms of the SSA production from blowing snow are discussed in Sect. 5.

\section{Measurements}

The measurements used for the model validation were carried out during a winter sea ice cruise in the Weddell Sea, Antarctica, aboard the German ice breaker RV Polarstern between 8 June and 12 August 2013 (Frey et al., 2019; Nerentorp Mastromonaco et al., 2016). The ship entered the sea ice zone on 17 June and penetrated into the Weddell Sea. From 20 July, the ship headed back to the marginal sea ice zone before re-entering the pack ice again around the 24 July and finally returning to the open ocean on 9 August. The cruise track was such that a large part of the measurements was carried out during polar night, since the sun remained below the horizon between 23 June and 7 July, providing only a few hours of twilight per day. A detailed description of instrumentation and measurement methods is given in an accompanying paper (Frey et al., 2019). In brief, airborne aerosol and suspended snow particle number concentrations at ambient temperature and humidity were continuously measured from the crow's nest of the ship at $29 \mathrm{~m}$ above the sea surface at 1 min temporal resolution. Meteorological parameters were measured by the ship's meteorology observatory and included air temperature and relative humidity at $29 \mathrm{~m}$ and wind speed and direction at $39 \mathrm{~m}$ above the sea ice surface (Fig. 1b-d). Aerosol particles were detected using a Compact Lightweight Aerosol Spectrometer (CLASP) and binned into 16 size bins covering the median diameter range from 0.36 to $11.62 \mu \mathrm{m}$ (Hill et al., 2008; Norris et al., 2008). Suspended blowing-snow particles were measured using a snow particle counter (SPC) described previously (Nishimura and Nemoto, 2005; Nishimura et al., 2014) with 64 size bins covering median diameters from 36 to $490 \mu \mathrm{m}$. Due to measurement uncertainty the SPC counts from the top and bottom bin are not used.

\section{Model and parameterization of SSA from SIZ}

\subsection{Model setup}

Our global chemistry transport model, p-TOMCAT, has a detailed process-based SSA scheme (Levine et al., 2014). The following updates have been introduced to this model in recent studies: more realistic model precipitation fields (Legrand et al., 2016), a sea spray emission scheme following the work of Jaeglé et al. (2011) and a modified surface snow salinity distribution function (Rhodes et al., 2017). Both open-ocean-sourced and sea-ice-sourced SSA (as dry $\mathrm{NaCl}$ ) are tagged in 21 size bins with size ranging from 0.02 to $12 \mu \mathrm{m}$ in order to track their relative contributions. For those ultra-fine particles (e.g. $<0.1 \mu \mathrm{m}$ ), the below-cloud scavenging coefficient rates are taken from the Dick (1990) scheme.

The meteorological forcing files for the model are 6-hourly reanalysis ERA-Interim data from the European Centre for 


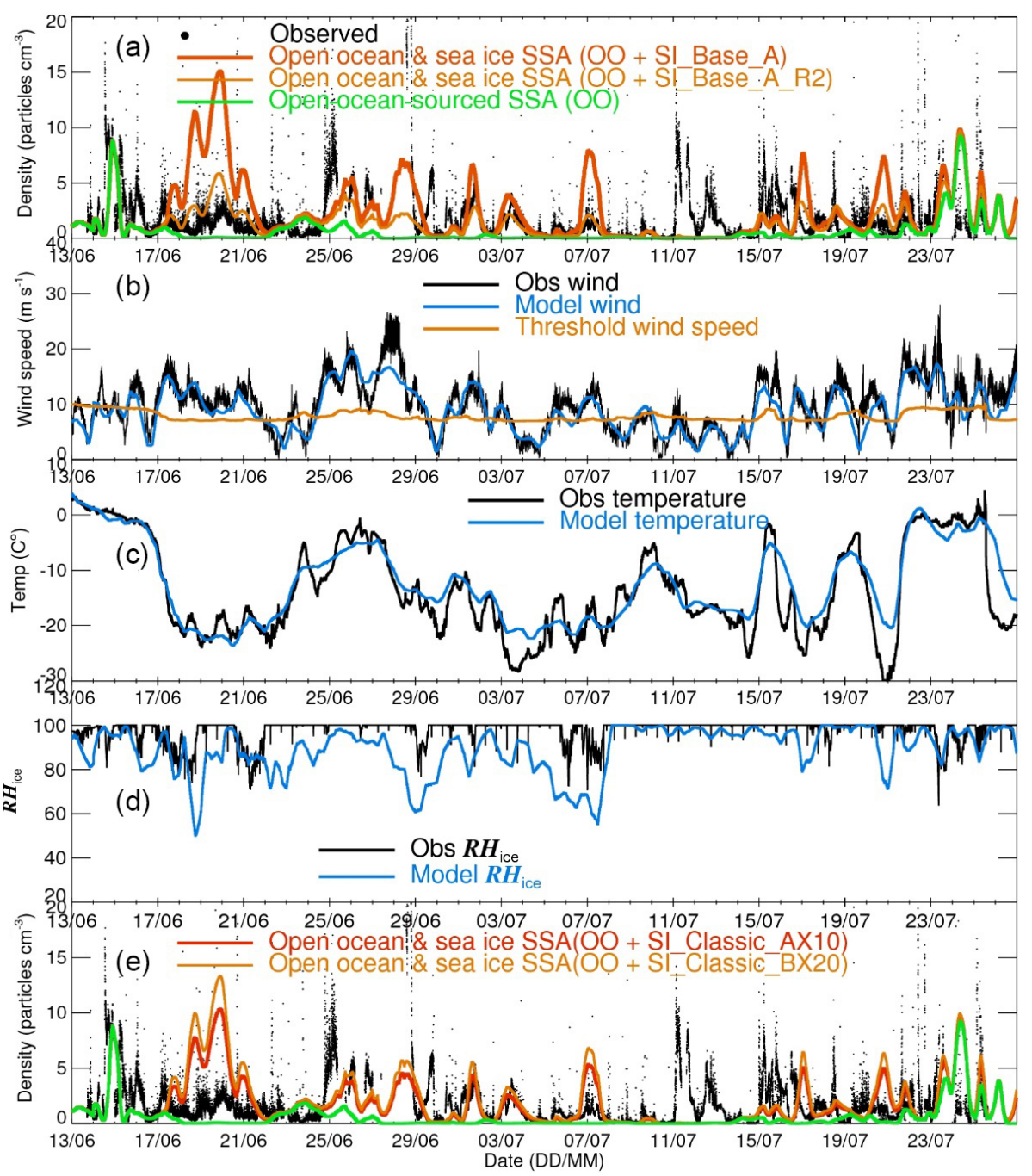

Figure 1. (a) Time series of total aerosol number densities from observations along the cruise track (refer to Fig. 1 in Frey et al., 2019) and model output of SI_Base_A (control run) and SI_Base_R2 (with a fixed surface RH with respect to ice equal to $95 \%$ ). Note that only SSAs with sizes overlapping with the observation $(\sim 0.4-12 \mu \mathrm{m})$ are counted. Meteorological data of wind speeds (b), temperatures (c) and relative humidity with respect to ice from both observation and model are shown. Calculated threshold wind speed for blowing snow is given in (b). Panel (e) is the same as (a), apart from the model output of SI_Classic_AX10 and SI_Classic_BX20.

Medium-Range Weather Forecasts (ECMWF). Monthly sea ice coverage and sea surface temperatures (SSTs) are taken from the Hadley Centre Sea Ice and Sea Surface Temperature (HadISST) dataset (Rayner et al., 2003). The model's horizontal resolution is $2.8^{\circ} \times 2.8^{\circ}$ with 31 vertical layers from the surface to $\sim 10 \mathrm{hPa}$ at the top model layer. The bottom model layer has an average height of $\sim 60 \mathrm{~m}$. The spin-up time is $>1$ year to allow an equilibrium situation to be established. A 3-year integration (2013-2015) is used to obtain multi-year means.

The experiments carried out are summarized in Table 1. In the control run for sea-ice-sourced SSA (SI_Base_A) a constant water mass loss rate against time for the snow particle sublimation rate is assumed (see Sect. 3.3.1), and mode A (Fig. 2) is used to represent the blowing-snow- particle distribution function. There are three additional runs - SI_Classic, SI_Area and SI_Mass (included in the prefix of experimental names) - performed with the aim of investigating possible mechanisms involved in the SSA production (see Sect. 3.3.1). The control run for open-ocean sea spray is SI_Base_OO, following the scheme by Jaeglé et al. (2011).

Apart from the global modelling investigations, an idealized theoretical calculation of the SSA production flux is made to compare with the sea spray flux under the same wind speed of $12 \mathrm{~m} \mathrm{~s}^{-1}$, as discussed in Sect. 5 . 
Table 1. Model experiments for sea-ice-sourced SSA (with SI in prefix of each experiment) and sea spray fluxes (with OO in the prefix). Columns 2-10 show parameters applied to each experiment: sublimation function, shape of the blowing-snow size distribution, ratio of SSA formed per blowing-snow particle, snow age, salinity, threshold wind speed, RH (with respect to ice) and air temperature.

\begin{tabular}{|c|c|c|c|c|c|c|c|c|c|}
\hline Model experiments & $\begin{array}{l}\mathrm{d} m_{\mathrm{i}} / \mathrm{d} t \\
\text { (sublima- } \\
\text { tion rate as } \\
\text { a function } \\
\text { of diameter } \\
\left.d_{\mathrm{i}}\right)\end{array}$ & $\begin{array}{l}\text { Shape } \alpha \\
(\alpha \times \beta= \\
140 \mu \mathrm{m}, \\
\text { mean } \\
\text { diame- } \\
\text { ter })\end{array}$ & $\begin{array}{l}\text { Ratio of } \\
\text { SSA per } \\
\text { blowing- } \\
\text { snow } \\
\text { particle }\end{array}$ & $\begin{array}{l}\text { Snow age } \\
\text { (day) }\end{array}$ & $\begin{array}{l}\text { Snow } \\
(\mathrm{psu})\end{array}$ & $\begin{array}{l}\text { Threshold wind } \\
\text { speed }\left(\mathrm{m} \mathrm{s}^{-1}\right)\end{array}$ & $\begin{array}{l}\text { Surface wind } \\
\text { speed }\left(\mathrm{m} \mathrm{s}^{-1}\right)\end{array}$ & $\begin{array}{l}\text { RH (\%) with } \\
\text { respect to ice }\end{array}$ & $\begin{array}{l}\text { Surface tem- } \\
\text { perature }\left({ }^{\circ} \mathrm{C}\right)\end{array}$ \\
\hline SI_Base_A & constant & 2 & 1 & 1.5 & full distribution & calculated & ERA-Interim & ERA-Interim & ERA-Interim \\
\hline SI_Base_A_R1 & constant & 2 & 1 & 1.5 & full distribution & calculated & ERA-Interim & 90 & ERA-Interim \\
\hline SI_Base_A_R2 & constant & 2 & 1 & 1.5 & full distribution & calculated & ERA-Interim & 95 & ERA-Interim \\
\hline SI_Base_A_T1 & constant & 2 & 1 & 1.5 & full distribution & 7 & ERA-Interim & ERA-Interim & ERA-Interim \\
\hline SI_Base_A_T2 & constant & 2 & 1 & 1.5 & full distribution & 8 & ERA-Interim & ERA-Interim & ERA-Interim \\
\hline SI_Base_A_T3 & constant & 2 & 1 & 1.5 & full distribution & 9 & ERA-Interim & ERA-Interim & ERA-Interim \\
\hline SI_Base_A_SN & constant & 2 & 1 & 1.5 & $\begin{array}{l}\text { distribution, } \\
\text { without }>10 \mathrm{psu}\end{array}$ & calculated & ERA-Interim & ERA-Interim & ERA-Interim \\
\hline SI_Base_A_SH & constant & 2 & 1 & 1.5 & 0.92 & calculated & ERA-Interim & ERA-Interim & ERA-Interim \\
\hline SI_Base_A_SL & constant & 2 & 1 & 1.5 & 0.06 & calculated & ERA-Interim & ERA-Interim & ERA-Interim \\
\hline SI_Base_B & constant & 3 & 1 & 1.5 & full distribution & calculated & ERA-Interim & ERA-Interim & ERA-Interim \\
\hline SI_Classic_A & $d_{\mathrm{i}}$ & 2 & 1 & 1.5 & full distribution & calculated & ERA-Interim & ERA-Interim & ERA-Interim \\
\hline SI_Classic_AX10 & $d_{\mathrm{i}}$ & 2 & 10 & 1.5 & full distribution & calculated & ERA-Interim & ERA-Interim & ERA-Interim \\
\hline SI_Classic_B & $d_{\mathrm{i}}$ & 3 & 1 & 1.5 & full distribution & calculated & ERA-Interim & ERA-Interim & ERA-Interim \\
\hline SI_Classic_BX20 & $d_{\mathrm{i}}$ & 3 & 20 & 1.5 & full distribution & calculated & ERA-Interim & ERA-Interim & ERA-Interim \\
\hline SI_Mass_A & $d_{i}^{3}$ & 2 & 1 & 1.5 & full distribution & calculated & ERA-Interim & ERA-Interim & ERA-Interim \\
\hline SI_Area_A & $d_{\mathrm{i}}^{1}$ & 2 & 1 & 1.5 & full distribution & calculated & ERA-Interim & ERA-Interim & ERA-Interim \\
\hline SI_Base_Aa & constant & 2 & 1 & 0 & 0.06 & calculated & 12 & 80 & -10 \\
\hline SI_Classic_Aa & $d_{\mathrm{i}}$ & 2 & 1 & 0 & 0.06 & calculated & 12 & 80 & -10 \\
\hline SI_Classic_AaX10 & $d_{\mathrm{i}}$ & 2 & 10 & 0 & 0.06 & calculated & 12 & 80 & -10 \\
\hline SI_Mass_Aa & $d_{i}^{3}$ & 2 & 1 & 0 & 0.06 & calculated & 12 & 80 & -10 \\
\hline SI_Area_Aa & $d_{i}^{2}$ & 2 & 1 & 0 & 0.06 & calculated & 12 & 80 & -10 \\
\hline $\mathrm{OO}$ & - & - & - & - & - & - & ERA-Interim & ERA-Interim & ERA-Interim \\
\hline OO_Jaeglé & - & - & - & - & - & - & 12 & - & - \\
\hline OO_Caffrey & - & - & - & - & - & - & 12 & - & - \\
\hline
\end{tabular}

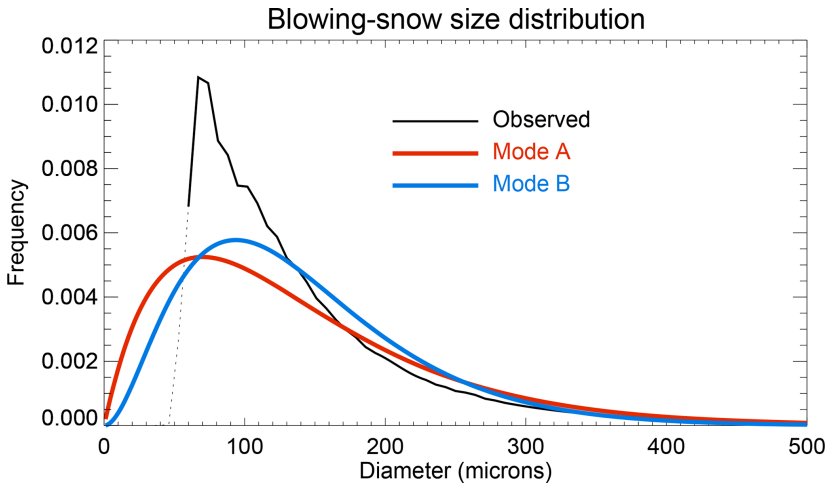

Figure 2. Normalized $29 \mathrm{~m}$ SPC instrumental blowing-snow size distribution is shown by the black line. Note that the dotted line is for small particles with a diameter $<60 \mu \mathrm{m}$. Two blowing-snow size distribution functions are derived for model usage with mode $\mathrm{A}$ (red line) having a shape value $\alpha=2$ with $\beta=70 \mu \mathrm{m}$ and mode $\mathrm{B}$ (blue line) having $\alpha=3$ with $\beta=46.7 \mu \mathrm{m}$ (fixed mean diameter $=140 \mu \mathrm{m})$. The $X$-axis interval is $10 \mu \mathrm{m}$.

\subsection{Parameterizations of SSA from SIZ}

\subsubsection{SSA flux}

According to the scheme proposed in Yang et al. (2008, 2010), the SSA flux from blowing snow is proportional to the bulk sublimation flux $Q_{\mathrm{s}}\left(\mathrm{kg} \mathrm{m}^{-2} \mathrm{~s}^{-1}\right)$ and snow salinity $\varsigma$ (in units of psu, practical salinity unit, normally measured in grams of salt per kilogram sea water). The bulk sublimation flux $Q_{\mathrm{s}}$ can be calculated following the approach of Déry and Yau (1999, 2001), when environmental factors, such as wind speed, relative humidity (RH) and air temperature, are given.

In order to demonstrate how to calculate the SSA flux from the bulk sublimation flux, here we simplify things by assuming (1) all snow particles have a uniform salinity $\varsigma$ (e.g. $0.06 \mathrm{psu}$, close to the median salinity from the field data, or 0.92 psu, close to the mean salinity) and (2) one blown-snow particle only produces one SSA after sublimation. This unit ratio $(=1)$ assumption dictates a low bound of SSA number production.

Under the above assumption, the corresponding dry $\mathrm{NaCl}$ size, $d_{\mathrm{dry}}$, for a snow particle with an initial diameter of $d_{\mathrm{i}}$ and salinity of $\varsigma$ can be derived as 
$d_{\mathrm{dry}}=d_{\mathrm{i}}\left(\frac{\varsigma \rho_{\mathrm{ice}}}{1000 \rho_{\mathrm{NaCl}}}\right)^{1 / 3}$,

where $\rho_{\text {ice }}\left(917 \mathrm{~kg} \mathrm{~m}^{-3}\right)$ is the density of ice and $\rho_{\mathrm{NaCl}}$ $\left(2160 \mathrm{~kg} \mathrm{~m}^{-3}\right)$ is density of $\mathrm{NaCl}$. Note that the factor 1000 applied in Eq. (1) converts units of psu to kilogram salt per kilogram sea water.

At steady state, the SSA number production flux, $F_{\text {SSA }}\left(d_{\text {dry }}\right)$ (particles $\mathrm{m}^{-2} \mathrm{~s}^{-1}$ ), should equal the snow particle loss rate via sublimation and the replenishment rate of supplied newly generated blowing-snow particles, $F_{\text {Snow }}\left(d_{\mathrm{i}}\right)$ (particles $\mathrm{m}^{-2} \mathrm{~s}^{-1}$ ). Thus, in a given snow size bin, with the corresponding sublimation flux $Q_{\mathrm{s}}\left(d_{\mathrm{i}}\right)$, we have these two fluxes:

$F_{\text {Snow }}\left(d_{\mathrm{i}}\right)=F_{\text {SSA }}\left(d_{\text {dry }}\right)=\frac{Q_{\mathrm{s}}\left(d_{\mathrm{i}}\right)}{M_{\mathrm{H}_{2} \mathrm{O}}\left(d_{\mathrm{i}}\right)}$,

where $M_{\mathrm{H}_{2} \mathrm{O}}\left(d_{\mathrm{i}}\right)$ is water mass in a snow particle with diameter of $d_{\mathrm{i}}$.

$M_{\mathrm{H}_{2} \mathrm{O}}\left(d_{\mathrm{i}}\right)=\frac{1}{6} \pi d_{\mathrm{i}}^{3} \rho_{\text {ice }}$.

For the SSA mass flux (in $\mathrm{kg} \mathrm{NaCl} \mathrm{m}^{-2} \mathrm{~s}^{-1}$ ) at dry diameter $d_{\text {dry }}$, we have

$Q_{\mathrm{SSA}}\left(d_{\mathrm{dry}}\right)=F_{\mathrm{SSA}}\left(d_{\mathrm{dry}}\right) M_{\mathrm{SSA}}\left(d_{\mathrm{dry}}\right)$,

where $M_{\mathrm{SSA}}\left(d_{\mathrm{dry}}\right)$ is the mass of SSA particles with size $d_{\mathrm{dry}}$.

$M_{\mathrm{SSA}}\left(d_{\mathrm{dry}}\right)=\frac{1}{6} \pi d_{\mathrm{dry}}^{3} \rho_{\mathrm{NaCl}}$

Incorporating above Eqs. (1)-(3) and (5), Eq. (4) can be rewritten as

$Q_{\mathrm{SSA}}\left(d_{\mathrm{dry}}\right)=Q_{\mathrm{s}}\left(d_{\mathrm{i}}\right) \frac{\varsigma}{1000}$,

which means the $\mathrm{NaCl}$ mass flux is proportional to snow salinity and the corresponding sublimation flux.

Obviously, how to derive $Q_{\mathrm{s}}\left(d_{\mathrm{i}}\right)$ for each snow size bin from the bulk sublimation flux $Q_{\mathrm{s}}$ is key in the parameterization because it determines the size distribution of sea salt aerosol. As proposed, it needs two relevant parameters: (1) blowing-snow size distribution function $f\left(d_{\mathrm{i}}\right)$; and (2) snow particle mass loss rate, namely $\frac{\mathrm{d} m_{\mathrm{i}}}{\mathrm{d} t}$, with $m_{\mathrm{i}}$ the mass of a snow particle at a size of $d_{\mathrm{i}}$. At steady state, when snow size distribution does not change with time, the combination term, $f\left(d_{\mathrm{i}}\right) \frac{\mathrm{d} m_{\mathrm{i}}}{\mathrm{d} t}$, could represent the water loss rate for all-size particles. Unlike $f\left(d_{\mathrm{i}}\right), \frac{\mathrm{d} m_{\mathrm{i}}}{\mathrm{d} t}$ is normally expressed in a non-normalized function; thus to allow a proper allocation, a normalization calculation for term $f\left(d_{\mathrm{i}}\right) \frac{\mathrm{d} m_{\mathrm{i}}}{\mathrm{d} t}$ is needed first. This can be done via a simple approach.

$f_{\text {norm }}\left(d_{\mathrm{i}}\right)=\frac{f\left(d_{\mathrm{i}}\right) \frac{\mathrm{d} m_{\mathrm{i}}}{\mathrm{d} t}}{\sum_{i=1}^{n} f\left(d_{\mathrm{i}}\right) \frac{\mathrm{d} m_{\mathrm{i}}}{\mathrm{d} t}}$, where $n$ is the number of snow size bins. Note that, at $\frac{\mathrm{d} m_{\mathrm{i}}}{\mathrm{d} t} \propto$ constant, $f_{\text {norm }}\left(d_{\mathrm{i}}\right)=f\left(d_{\mathrm{i}}\right)$.

With Eq. (7), the bulk sublimation flux can be allocated into each snow size bin.

$Q_{\mathrm{s}}\left(d_{\mathrm{i}}\right)=Q_{\mathrm{s}} f_{\text {norm }}\left(d_{\mathrm{i}}\right)$

Then the SSA flux in Eq. (6) can be re-expressed as

$Q_{\mathrm{SSA}}\left(d_{\mathrm{dry}}\right)=Q_{\mathrm{s}} f_{\text {norm }}\left(d_{\mathrm{i}}\right) \frac{\varsigma}{1000}$.

It is likely that snow salinity is not constant in time, as the accumulated snow represents successive snowfalls and perhaps the influence of intermittent inputs from wind-blown sea spray and flooding. In this scenario, snow salinity is instead represented by a frequency distribution, $\psi(\varsigma)$, and the integrated SSA production flux can be expressed as

$Q_{\mathrm{SSA}}=Q_{\mathrm{s}} \iint f_{\text {norm }}\left(d_{\mathrm{i}}\right) \psi(\varsigma) \frac{\varsigma}{1000} \mathrm{~d}\left(d_{\mathrm{i}}\right) \mathrm{d} \varsigma$.

Comparing to Eq. (8) in Yang et al. (2008), we can find that the one in Yang et al. (2008) is a simplified version of the above equation at a condition of $\frac{\mathrm{d} m_{\mathrm{i}}}{\mathrm{d} t} \propto$ constant.

If more than one SSA is formed per snow particle, and assuming they are all equal in size, then at a ratio of $N$ the corresponding dry $\mathrm{NaCl}$ size will be

$d_{\mathrm{dry}}^{*}=\left(\frac{1}{N}\right)^{1 / 3} d_{\mathrm{i}}\left(\frac{\varsigma \rho_{\text {ice }}}{1000 \rho_{\mathrm{NaCl}}}\right)^{1 / 3}$.

Under this condition, the SSA number flux will be simply $N$ times of the flux in Eq. (2) at $N=1$.

Figure 3 shows the equivalent dry $\mathrm{NaCl}$ diameter $(\mu \mathrm{m})$ as a function of initial snow particle diameter $(\mu \mathrm{m})$ and snow salinity (psu) calculated following Eqs. (1) or (11) at $N=1$. For an initial snow particle $d_{\mathrm{i}}=10 \mu \mathrm{m}$, the SSAs formed at salinity $<10 \mathrm{psu}$ are submicron sized; at a low salinity of $<0.01 \mathrm{psu}$, the SSAs are $<0.1 \mu \mathrm{m}$. For a larger snow particle $d_{\mathrm{i}}=100 \mu \mathrm{m}$ (close to the median size of the blowing snow), the SSAs formed are mainly in the range of $1-10 \mu \mathrm{m}$ at salinity ranging from 0.01 to $10 \mathrm{psu}$; at an even lower salinity of $<0.01 \mathrm{psu}$, the SSAs are submicron sized. Note that, at $N=\sim 10$, the corresponding dry SSA size will be roughly half of the value at $N=1$.

\subsubsection{Blowing-snow-particle flux}

As pointed out above, at steady state, the snow particle loss rate via the sublimation process should be balanced by newly supplied/generated blowing-snow particles for each size bin to keep the snow particle size distribution unchanged with time. In windy conditions, vertical mixing via eddy turbulence is relatively fast; thus the timescale of mixing could be much shorter than that for the sublimation process. For instance, for a droplet with a size of tens of microns, to evaporate it completely may take a few thousands of seconds (Mason, 1971), which is substantially longer than the timescale 


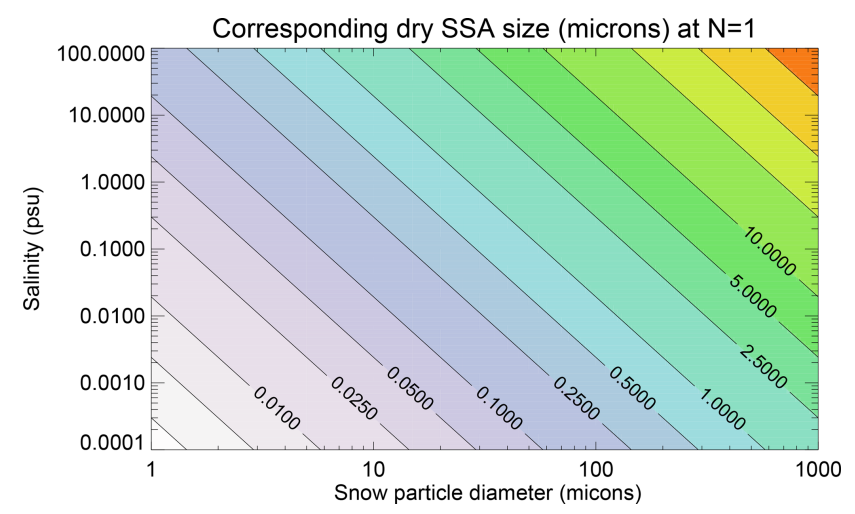

Figure 3. Equivalent dry SSA diameter $(\mu \mathrm{m})$ as a function of initial snow particle diameter $(\mu \mathrm{m})$ and snow salinity $(\mathrm{psu})$ at $N=1$, calculated following Eq. (11).

of tens to hundreds of seconds in boundary layer turbulent mixing (Caughey et al., 1979). Therefore, the newly generated small snow crystals could be efficiently brought upwards, via rebound and splashing of snow grains in the saltation layer $(<0.1 \mathrm{~m})$, to replenish sublimated ones. Under the assumption that one blowing-snow particle only forms one SSA, then Eq. (2) can be used to describe the flux of the blowing-snow-particle production rate.

\subsection{Parameters and model experiments}

\subsubsection{Sublimation function}

As shown in Table 1, there are four sublimation functions applied to the $\frac{\mathrm{d} m_{\mathrm{i}}}{\mathrm{d} t}$ term to deal with bulk sublimation allocation. All control runs (with SI_Base in the prefix) apply a function of $\frac{\mathrm{d} m_{\mathrm{i}}}{\mathrm{d} t} \propto$ constant (across size bins) in Eq. (7). This water loss rate can be re-expressed as $\frac{\mathrm{d} r}{\mathrm{~d} t} \propto \frac{1}{r^{2}}$ with $r$ representing the radius of a spherical crystal of equivalent mass $m$. There are two possible physical processes that could cause this relationship. The first is the so-called Kelvin curvature effect (Pruppacher and Klett, 1997), in which vapour pressure is higher above a curved surface so that small particles evaporate faster than large ones, and indeed in some circumstances large particles may actually grow at the expense of small ones. The second is the so-called "air ventilation" effect, a process that can accelerate particle sublimation rate in turbulent air. For example, in an airflow tube experiment under subsaturation, crystals with size ranging from 0.3 to $1.3 \mathrm{~mm}$ show a linear water mass loss rate (against time) (Thorp and Mason, 1967), suggesting that smaller particles are losing mass at the same rate as larger ones.

In SI_Classic runs (with SI_Classic in the prefix), a simple relation function of $\frac{\mathrm{d} m_{\mathrm{i}}}{\mathrm{d} t} \propto d_{\mathrm{i}}$ (or equally $\frac{\mathrm{d} r}{\mathrm{~d} t} \propto \frac{1}{r}$ ) is applied. This is a sublimation rate for particles at a stationary condition (e.g. not moving relative to the surrounding air), at which water loss rate is controlled by the moisture gradient between the particle surface and the ambient air (Houghton,
1933). As shown in Sects. 4 and 5, SI_Classic runs allocate relatively less water to smaller snow size bins than SI_Base runs and therefore produce fewer submicron-sized SSAs (the break-up effect is not considered here).

A third sublimation function of $\frac{\mathrm{d} m_{\mathrm{i}}}{\mathrm{d} t} \propto d_{\mathrm{i}}^{3}$ (or $\frac{\mathrm{d} r}{\mathrm{~d} t} \propto r$ ) is investigated (denoted as SI_Mass). Note that there is no actual microphysical process within the blowing-snow layer that can be assigned to match this function, but it would be the case if an air parcel, including blowing snow unsorted by particle size, came into contact with subsaturated air so that the entire population became aerosol. If this occurred, then the SSA size distribution would be the same as the suspended blowing-snow particles (from a snapshot of the blowing-snow layer) that lose water completely.

A fourth function of $\frac{\mathrm{d} m_{\mathrm{i}}}{\mathrm{d} t} \propto d_{\mathrm{i}}^{2}$ (or $\frac{\mathrm{d} r}{\mathrm{~d} t} \propto$ constant) is also investigated (denoted as SI_Area). Again, we could not assign an actual microphysical process to match it, but as it expresses in this function, it implies that the water loss rate is simply proportional to the particle surface area.

We hope that, by comparing the SSA size spectrum between model integrations and the observations, we may assess which of these functions could be most appropriate.

\subsubsection{Blowing-snow size distribution}

It has been found that suspended blowing-snow particles follow a two-parameter gamma distribution function $f\left(d_{\mathrm{i}}, \alpha, \beta\right)$, with the $\alpha$ shape parameter and $\beta$ scale parameter following a simple relationship of $\alpha \beta=D$, where $D$ is mean diameter in microns of blown-snow particles (e.g. Schmidt, 1982; Dover, 1993).

$f\left(d_{\mathrm{i}}, \alpha, \beta\right)=\frac{e^{-\frac{d_{\mathrm{i}}}{\beta}} d_{\mathrm{i}}^{\alpha-1}}{\beta^{\alpha} \Gamma(\alpha)}$

The SPC instrument mounted at the crow's nest showed a mean snow particle diameter of $\sim 140 \mu \mathrm{m}$ with $\alpha$ of $2-3$ on average (Fig. 2). The SPC instrument samples snow particles in the range of 46-500 $\mu \mathrm{m}$, but, due to the large background noise from the smallest $(\sim 46 \mu \mathrm{m})$ and largest $(\sim 500 \mu \mathrm{m})$ size bin, these two bins are not included in the data analysis and comparison. They are comparable to the snow data collected at Halley station, a coastal site in the Weddell Sea, with $\alpha=2$ and mean diameter of $\sim 150 \mu$ m (Mann et al., 2000).

The $\alpha$ value can vary from site to site and normally increases with increasing altitude from the surface (e.g. Nemoto and Nishimura, 2004). It is unlikely that $\alpha$ can be less than 1 , as $\alpha=1$ means the gamma distribution function will decay to an exponential function, which is not appropriate in describing blowing-snow particles. Due to the lack of instrumental data at a size of $<46 \mu \mathrm{m}$, we could not precisely describe the blowing-snow size distribution function. For this reason, two distribution modes are applied (Fig. 2): mode A having $\alpha=2$ with $\beta=70 \mu \mathrm{m}$ and mode B having 
$\alpha=3$ with $\beta=46.7 \mu \mathrm{m}$ (both with a fixed mean diameter of $140 \mu \mathrm{m}$ ). Note that the two gamma functions (modes A and B) cannot be used to compare directly to the observed data (black line, Fig. 2) because of different sampling size ranges used in their normalization calculations.

\subsubsection{Snow salinity}

Similar to the previous modelling study by Rhodes et al. (2017), a surface snow salinity distribution is applied (e.g. see Fig. 12 of Frey et al., 2019), which is based on surface snow samples (top $10 \mathrm{~cm}$ ) collected in the Weddell Sea SIZ. In the Arctic, snow salinity values are trebled to reflect the likelihood that snow there is more saline than in the Antarctic due to reduced precipitation rate (Yang et al., 2008). Further, we make the rate of SSA emission from multi-year sea ice half that from first-year sea ice (Rhodes et al., 2017). We note that these assumptions will not affect the main conclusions of this study.

As reflected in Eq. (1), SSA size is proportional to salinity with a power of $1 / 3$; thus for a 10 -fold change in salinity, dry $\mathrm{NaCl}$ size only alters by a factor of $\sim 2$. However, since snow salinity can vary by orders of magnitude, e.g. from the lowest values of $10^{-3}$ to more than $100 \mathrm{psu}$, snow salinity is an important factor in determining both SSA size and mass loading. To test model sensitivity to this factor, two fixed snow salinity experiments are performed, with SI_Base_A_SL applying a fixed low value of $0.06 \mathrm{psu}$ (median) and SI_Base_A_SH a high salinity of $0.92 \mathrm{psu}$ (mean). We also include an experiment to test the sensitivity to highly saline snow samples, e.g. with salinity $>10 \mathrm{psu}$, which account for $\sim 4 \%$ of total snow samples as measured. SI_Base_A_SN is the same as SI_Base_A but without samples at salinity $>10 \mathrm{psu}$ (Table 1 ).

\subsubsection{Snow age}

How snow age affects blowing snow and SSA production is not completely clear, though it has generally been thought that aged snow will be more resistant to wind mobilization (Li and Pomeroy, 1997; Box et al., 2004). Snow age was initially introduced to the parameterization to counteract the relatively high snow salinity used (Yang et al., 2008). At present, this parameter amounts to a crude tuning tool with no clear physical meaning. Snow age $=0$ gives the largest coefficient $(=1)$ to the production flux; therefore, by setting snow age to zero, we effectively remove this parameter altogether. Note that "snow age" should not be interpreted as the time elapsed after the snowfall.

Actually, the "snow" here refers to all ice crystals on the surface snowpack that can be uplifted by air movement. These include fresh fallen snow, diamond dust, wind-cropped frosts or even aged snow that has been re-mobilized by wind erosion. The mixing of fresh snow and old saline snow changes the salinity distribution, a process that has not been considered by the model so far. Due to a lack of data, we do not know how fast fresh fallen snow acquires salts. This process may be fast and efficient during windy conditions through direct physical contact with salt-rich crystals. With further data, we may have a better representation of this process.

Here in this study, we follow a recent study by Huang and Jaeglé (2017) by setting a snow age $=1.5 \mathrm{~d}$ for the Southern Hemisphere and $3 \mathrm{~d}$ for the Northern Hemisphere, which is slightly different to our previously value of $1 \mathrm{~d}$ in both hemispheres (Rhodes et al., 2017). This change causes reductions of $\sim 16 \%$ in the Southern Hemisphere and $\sim 39 \%$ in the Northern Hemisphere in the bulk sublimation flux.

\subsubsection{Relative humidity (RH)}

As pointed out by Mann et al. (2000), sublimated water from blowing-snow particles will raise the $\mathrm{RH}$ (with respect to ice) within the blowing-snow layer, which will have a negative effect on the further sublimation of wind-blown-snow particles, especially from the near-surface layer. A model without consideration of this negative feedback may likely overestimate sublimation and SSA production. The p-TOMCAT model gets its RH field directly from ECMWF ERA-Interim data. Therefore, it is likely that the model surface RH is underestimated in the cases with blowing snow. Figure 1c indicates that the lowest model grid box RHs (with respect to ice) (at an average height of $\sim 30 \mathrm{~m}$ ) are, on average, significantly lower than the observations, which may be responsible for some overestimated SSA events by the model. To test model sensitivity, two runs are performed, with SI_Base_A_R1 applying a fixed surface $\mathrm{RH}$ (with respect to ice) equal to $90 \%$ and SI_Base_A_R2 applying RH (with respect to ice) equal to $95 \%$ (Table 1). The SI_Base_A_R2 run result is shown in Fig. 1a (orange line).

\subsubsection{Threshold wind speed}

According to Li and Pomeroy (1997), the threshold wind speed for blowing snow is air temperature and snow age dependent. According to the bulk sublimation parameterization of Déry and Yau $(1999,2001)$, a minimum threshold of $\sim 7 \mathrm{~m} \mathrm{~s}^{-1}$ is obtained at an air temperature around $-27^{\circ} \mathrm{C}$. With the equation used, the threshold wind speed will be larger at either warmer or colder conditions. For example, at air temperatures of -10 and $0^{\circ} \mathrm{C}$, as experienced during the cruise, the model calculates a threshold wind speed of $\sim 8$ and $10 \mathrm{~m} \mathrm{~s}^{-1}$ respectively (Fig. 1b). Note that the above equation may overlook blowing-snow events at low wind speeds. For example, the onset of saltation or drifting snow can be observed at wind speeds of just a few metres per second for loose dry and/or unbounded fresh snow (e.g. Male, 1980; Pomeroy et al., 1993; King and Turner, 1997; Nemoto and Nishimura, 2004; Doorschot et al., 2004; Clifton et al., 2006). Since this process is not reflected by the model, 
it could explain those underestimated or completely missed SSA enhancement events, e.g. the aerosol spikes occurring during 11-13 July (Fig. 1a).

Due to the large perturbation in air temperature, the threshold wind speed calculated varies significantly in association with the temperature perturbation (orange line in Fig. 1b). To test model sensitivity to this term, model runs with fixed threshold speeds of 7,8 and $9 \mathrm{~m} \mathrm{~s}^{-1}$ (in SI_Base_A_T1, SI_Base_A_T2 and SI_Base_A_T3, respectively) (Table 1) are performed.

\subsubsection{SSA production ratio per snow particle}

In the original parameterizations (Yang et al., 2008), a unit ratio $(N=1)$ is assumed; namely, only one SSA is formed from one single snow particle. However, we cannot rule out the possibility that more than one SSA can be formed during the sublimation process, for example, by collision of snow particles in the saltation layer or the dynamical effect for snow particles in turbulent air. So far, this issue is quite unclear. A ratio of $N=5$ has been applied in a recent modelling study (Huang and Jaeglé, 2017) to allow a better agreement to the observations. Here we have two experiments, with $N=10$ in SI_Classic_AX10 and $N=20$ in SI_Classic_BX20. Results are discussed in Sect. 5 and shown in Table 2. Note that the selection of $N=10$ or 20 is arbitrary and simply a model experimental trial.

\section{Results of the model-data comparison}

\subsection{In the Weddell Sea}

Figure 1a shows a comparison of observed total aerosol number density along the cruise track and model output (size ranging from $\sim 0.4$ to $12 \mu \mathrm{m}$ ) from (i) the control run SI_Base_A, (ii) a reduced surface relative humidity experiment SI_Base_A_R2 (using only size bins overlapping the instrumental size) and (iii) the open-ocean sea spray source. Model results clearly indicate that sea spray (green line) dominated aerosol signals before the vessel entered the sea ice zone on 17 June; subsequently, sea-ice-sourced SSA played the dominant role of generating aerosol when the vessel entered deep into the SIZ.

For the full analysis, we have regrouped the cruise data into three surface types: open ocean (before 17 June), marginal sea ice and packed sea ice, using an air temperature of $-18^{\circ} \mathrm{C}$ as the threshold between marginal ice and packed sea ice. According to this classification, open ocean, marginal ice and packed sea ice account for $9 \%, 42 \%$ and $49 \%$, respectively, of the measurements. The corresponding mean air temperatures are $-0.8,-11$ and $-22^{\circ} \mathrm{C}$, with mean wind speeds of $9,10.3$ and $8 \mathrm{~m} \mathrm{~s}^{-1}$, for each zone. Note that a similar result can be obtained if the model's sea ice (or open water) coverage fraction is used for the classification (not shown). (a) Open ocean

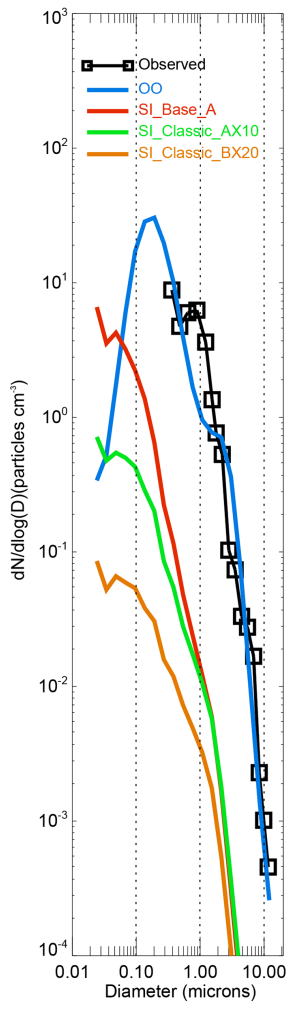

(b) Marginal ice

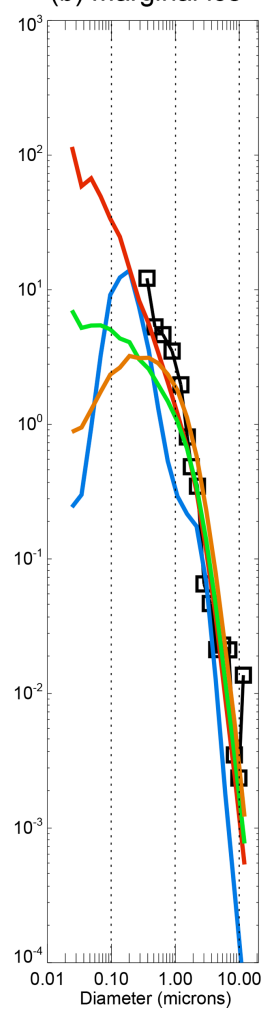

(c) Packed ice

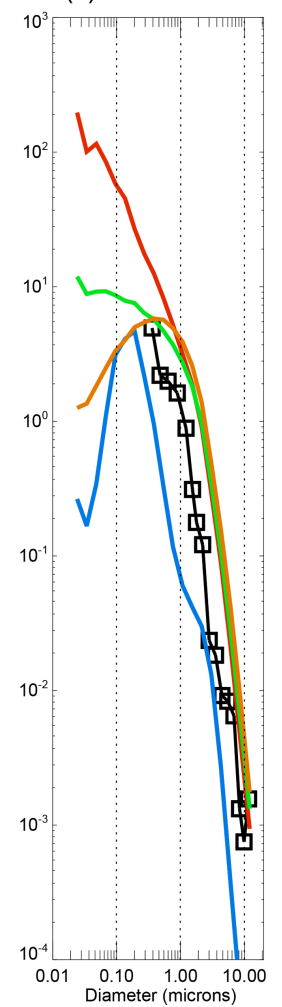

Figure 4. Size distribution of sea spray and sea-ice-soured SSA at three defined surface zones: (a) open ocean, (b) marginal sea ice, and (c) packed sea ice zone. Observations are shown by the black lines with box symbols. Open-ocean sea spray comes from the $\mathrm{OO}$ run (blue). Sea-ice-sourced SSA from the control run SI_Base_A (red) and two SI_Classic runs. Note that SI_Classic_AX10 (green) is the same as SI_Classic_A but applying a ratio of 10 SSA produced per blowing-snow particle; SI_Classic_BX20 (orange) is the same as SI_Classic_B but applying a ratio of 20 (Table 1). Vertical dashed lines represent a diameter of $0.1,10$ and $10 \mu \mathrm{m}$.

Figure 4 shows the simulated aerosol size spectrum in each surface zone. It can be seen that, over the open ocean (Fig. 4a), sea spray (OO, blue line) dominates over sea-ice-sourced SSA (in three model runs: SI_Base_A, SI_Classic_AX10 and SI_Classic_BX20). By looking at the time series, we find that sea spray shows a significant positive correlation to the observations with a correlation coefficient of $r=0.55$ (Table 2). The model-data ratio in Table 2 (for overlapping size range) suggests that the model underestimates the observation by $\sim 50 \%$ in the open-ocean zone.

Once the vessel enters densely packed sea ice (Fig. 4c), the simulated sea spray contribution drops significantly to only $\sim 10 \%$ and cannot explain the observations. Meanwhile, sea-ice-sourced SSA dominates, although the above three runs overestimate the observations with model-data ratios of 1.8-2.8. In addition, they all show a positive correlation to the observations with a coefficient $r>0.5$ (Table 2). 
Table 2. Ratios of aerosol number density between model runs and the observations (for overlapping size range of $0.4-12 \mu \mathrm{m}$ ) along the cruise track over the surface types open ocean (column 2), marginal sea ice (column 3) and packed sea ice (column 4). The values in brackets are the correlation coefficient between time series of model output and the observation at each surface zone.

\begin{tabular}{|c|c|c|c|}
\hline Experiments & $\begin{array}{l}\text { Ratio (model/obs) } \\
\text { over open ocean }\end{array}$ & $\begin{array}{l}\text { Ratio (model/obs) } \\
\text { over marginal ice }\end{array}$ & $\begin{array}{l}\text { Ratio (model/obs) } \\
\text { over packed ice }\end{array}$ \\
\hline $\mathrm{OO}$ & $0.50(r=0.55)$ & $0.19(r=0.14)$ & $0.10(r=0.33)$ \\
\hline SI_Base_A & $<0.01(r=0.14)$ & $0.47(r=0.25)$ & $2.76(r=0.55)$ \\
\hline OO+SI_Base_A & $0.50(r=0.55)$ & $0.66(r=0.28)$ & $2.86(r=0.56)$ \\
\hline SI_Base_A_R1 & $<0.01(r=0.14)$ & $0.45(r=0.26)$ & $1.82(r=0.63)$ \\
\hline $\mathrm{OO}+$ SI_Base_A_R1 & $0.50(r=0.55)$ & $0.64(r=0.27)$ & $1.92(r=0.64)$ \\
\hline SI_Base_A_R2 & $<0.01(r=0.14)$ & $0.27(r=0.26)$ & $1.10(r=0.62)$ \\
\hline $\mathrm{OO}+\mathrm{SI}$ _Base_A_R2 & $0.49(r=0.55)$ & $0.45(r=0.26)$ & $1.21(r=0.64)$ \\
\hline SI_Base_A_T1 & $0.02(r=0.14)$ & $0.98(r=0.29)$ & $3.57(r=0.58)$ \\
\hline $\mathrm{OO}+$ SI_Base_A_T1 & $0.50(r=0.55)$ & $1.17(r=0.30)$ & $3.67(r=0.58)$ \\
\hline SI_Base_A_T2 & $<0.01(r=0.14)$ & $0.43(r=0.33)$ & $1.27(r=0.53)$ \\
\hline $\mathrm{OO}+$ SI_Base_A_T2 & $0.50(r=0.55)$ & $0.62(r=0.32)$ & $1.38(r=0.56)$ \\
\hline SI_Base_A_T3 & $<0.01(r=0.14)$ & $0.22(r=0.34)$ & $0.53(r=0.50)$ \\
\hline $\mathrm{OO}+$ SI_Base_A_T3 & $0.50(r=0.55)$ & $0.40(r=0.30)$ & $0.63(r=0.54)$ \\
\hline SI_Base_A_SN & $<0.01(r=0.14)$ & $0.38(r=0.26)$ & $2.16(r=0.55)$ \\
\hline $\mathrm{OO}+$ SI_Base_A_SN & $0.50(r=0.55)$ & $0.56(r=0.28)$ & $2.27(r=0.56)$ \\
\hline SI_Base_A_SL & $<0.01(r=0.14)$ & $0.32(r=0.26)$ & $1.82(r=0.55)$ \\
\hline $\mathrm{OO}+$ SI_Base_A_SL & $0.50(r=0.55)$ & $0.50(r=0.28)$ & $1.92(r=0.56)$ \\
\hline SI_Base_A_SH & $0.01(r=0.14)$ & $0.94(r=0.25)$ & $5.46(r=0.54)$ \\
\hline $\mathrm{OO}+$ SI_Base_A_SH & $0.51(r=0.55)$ & $1.13(r=0.27)$ & $5.57(r=0.55)$ \\
\hline SI_Base_B & $<0.01(r=0.14)$ & $0.13(r=0.25)$ & $0.79(r=0.54)$ \\
\hline $\mathrm{OO}+$ SI_Base_B & $0.50(r=0.55)$ & $0.32(r=0.24)$ & $0.89(r=0.57)$ \\
\hline SI_Classic_A & $<0.01(r=0.14)$ & $0.05(r=0.25)$ & $0.28(r=0.53)$ \\
\hline $\mathrm{OO}+$ SI_Classic_A & $0.50(r=0.55)$ & $0.23(r=0.19)$ & $0.39(r=0.59)$ \\
\hline SI_Classic_AX10 & $<0.01(r=0.14)$ & $0.32(r=0.25)$ & $1.85(r=0.53)$ \\
\hline $\mathrm{OO}+$ SI_Classic_AX10 & $0.50(r=0.55)$ & $0.50(r=0.27)$ & $1.96(r=0.59)$ \\
\hline SI_Classic_B & $<0.01(r=0.14)$ & $0.02(r=0.25)$ & $0.15(r=0.52)$ \\
\hline $\mathrm{OO}+$ SI_Classic_B & $0.50(r=0.55)$ & $0.21(r=0.17)$ & $0.25(r=0.57)$ \\
\hline SI_Classic_BX20 & $<0.01(r=0.14)$ & $0.40(r=0.25)$ & $2.38(r=0.54)$ \\
\hline $\mathrm{OO}+$ SI_Classic_BX20 & $0.50(r=0.55)$ & $0.50(r=0.27)$ & $2.48(r=0.55)$ \\
\hline SI_Area_A & $<0.01(r=0.14)$ & $0.06(r=0.25)$ & $0.04(r=0.52)$ \\
\hline OO + SI_Area_A & $0.50(r=0.55)$ & $0.19(r=0.15)$ & $0.15(r=0.46)$ \\
\hline SI_Mass_A & $<0.01(r=0.14)$ & $<0.01(r=0.25)$ & $<0.01(r=0.49)$ \\
\hline $\mathrm{OO}+$ SI_Mass_A & $0.50(r=0.55)$ & $0.18(r=0.13)$ & $0.11(r=0.36)$ \\
\hline
\end{tabular}

In marginal sea ice (Fig. 4b), our simulations suggest that both sea-ice- and open-ocean-sourced SSA are making a contribution to the observations. However, neither sea-icesourced SSA nor sea spray alone shows a strong positive correlation with the observations. For example, the time series show only a small positive coefficient $r=0.25$ for all the three sea-ice-sourced SSAs with $r=0.14$ for sea spray. Their combined effect (sum of sea-ice-sourced SSA and sea spray) only shows a slight increase in the relationship coefficient with $r$ of $0.27-0.28$ (Table 2), indicating limited model ability in marginal ice SSA simulation. In the marginal ice zone, the model (sum of sea-ice- and open-ocean-sourced SSA) underestimates the observations by $\sim 30 \%$, as shown in the third column of Table 2 , where a ratio of 0.19 for sea spray (OO) and 0.47 for sea-ice-sourced SSA (SI_Base_A) is obtained. The lack of significant correlation in the marginal zone could be related to the large variations in air temperature and moisture in both temporal and spatial scales in this transitional surface zone. Moreover, since the parameterization for the bulk sublimation flux calculation was derived based on data at relatively colder and drier conditions, e.g. from the Canadian Prairies, whether it is applicable in warmer conditions, such as over sea ice, is not yet known.

Although the meteorological fields, such as wind speed (Fig. 1b), temperature (Fig. 1c) and moisture (Fig. 1d), taken from the ERA-Interim database, in general agree well with the observations, discrepancies between them can be large during specific time periods. On average, model surface wind speeds are lower than the observations, especially during storm events; this is because global models with a coarse spatial resolution suffer significant spatial averaging and cannot reproduce gusty winds. For example, a mean wind speed 
of $\sim 22 \mathrm{~m} \mathrm{~s}^{-1}$ is observed during 12:00 UTC on 27 June and 06:00 UTC on 28 June, which is $\sim 7 \mathrm{~m} \mathrm{~s}^{-1}$ higher than the lowest model layer wind speed (at $\sim 30 \mathrm{~m}$ ). This lower model wind speed means an underestimation in both sublimation and SSA by a factor of $\sim 2$. Given that the sublimation flux from blowing snow is a function of wind speed with a power of $\sim 3$, then the largest model underestimation for SSA production is likely associated with storm events.

At air temperatures of -35 to $-20^{\circ} \mathrm{C}$, the threshold wind speed for blowing snow (calculated from the Eq. 2 in Yang et al., 2008), stays low, e.g. $\sim 7 \mathrm{~m} \mathrm{~s}^{-1}$; however, it increases to $\sim 8 \mathrm{~m} \mathrm{~s}^{-1}$ at a temperature of $-10^{\circ} \mathrm{C}$ and $\sim 10 \mathrm{~m} \mathrm{~s}^{-1}$ at just below zero. At the marginal sea ice zone, air temperature suffers large perturbations, making threshold wind speed very variable (Fig. 1c), affecting both sublimation and then SSA production calculations. It is interesting to note that model runs with fixed threshold speed $\left(7 \mathrm{~m} \mathrm{~s}^{-1}\right.$ in SI_Base_A_T1 and $8 \mathrm{~m} \mathrm{~s}^{-1}$ in SI_Base_A_T2) show better agreement with the observations in the marginal ice zone, with correlation coefficients increased from the control run $r=0.25$ to $\sim 0.3$ in those two runs (Table 2). The combined results from sea spray and sea-ice-sourced SSA show a similar result, e.g. from $r=0.28$ (in OO+SI_Base_A) to 0.30 (in $\mathrm{OO}+$ SI_Base_A_T1) and 0.32 (in OO+SI_Base_A_T2). As a result, the SSA number densities in SI_Base_T1 show an increase of $\sim 50 \%$ over both the marginal and packed sea ice zones. In the SI_Base_A_T2 run, the concentrations drops by $40 \%-50 \%$. At an even higher threshold of $9 \mathrm{~m} \mathrm{~s}^{-1}$ (in SI_Base_A_T3), the SSA production from blowing snow is strongly suppressed (Table 2).

During 11-13 July, there are two large aerosol enhancement events which are completely overlooked by the model. As shown in Fig. 1b, they correspond to relatively low wind speeds (in both reality and model), lower than the calculated threshold speed of $7 \mathrm{~m} \mathrm{~s}^{-1}$. However, as discussed in Sect. 3.3.6, drifting snow can be measured at low wind speeds of just a few metres per second when snow particles are loose and unbounded, a process which has not been considered by the model. This possibly explains why the model fails to reproduce these two aerosol spiking events.

Apart from wind, moisture is another key factor that influences both sublimation and SSA production. As shown in Fig. 1d, model RHs are generally lower than the observations, which is likely due to the model not considering the negative feedback of sublimated water vapour to the near-surface blowing-snow layer, which will limit further water loss from suspended snow particles. Obviously, models without considering this feedback effect could result in the overestimation of the SSA flux in some circumstances. We perform two model experiments with fixed surface RH (with respect to ice) equal to $90 \%$ in SI_Base_A_R1 and $95 \%$ in SI_Base_A_R2 to investigate this issue. As reflected in Fig. 1a (orange line, with RH (with respect to ice) equal to $95 \%$ ) and Table 2, these two models results are much closer to the observations. For instance, the model-
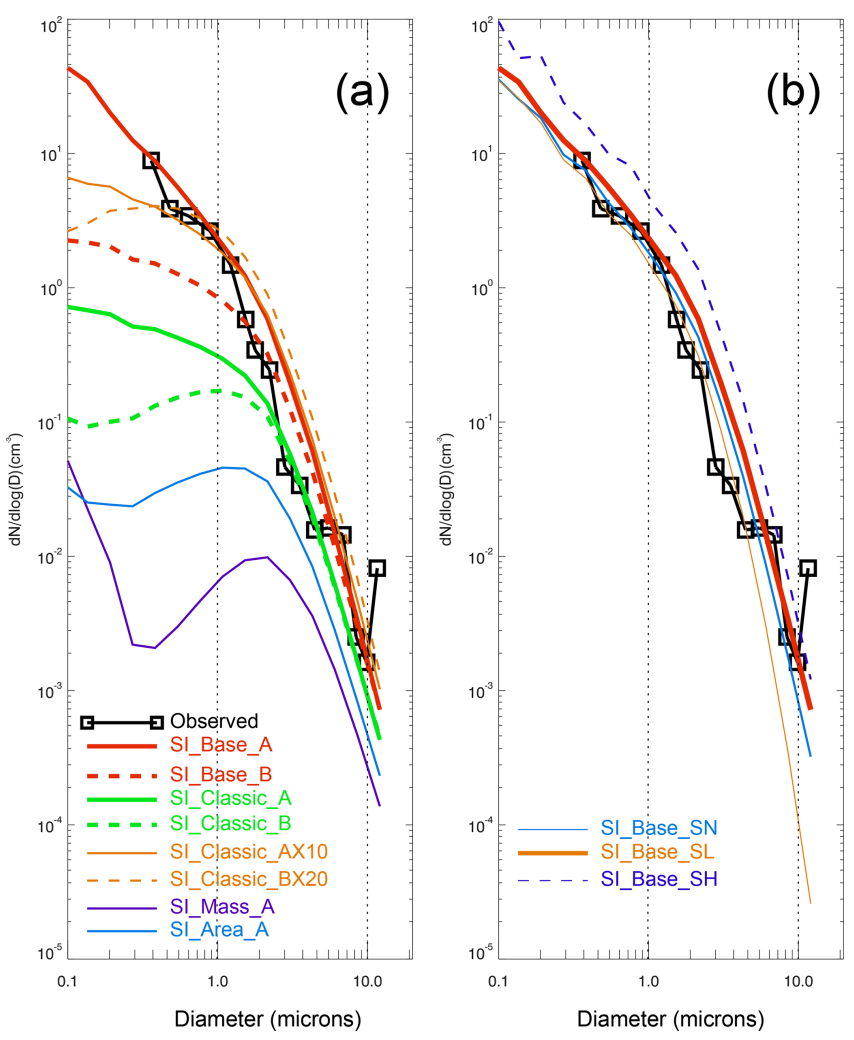

Figure 5. Averaged SSA size distribution from the whole sea ice zone (including both marginal and packed sea ice). Observations are shown in the black line with box symbols. Panel (a) contains model runs with different parameters, including four different sublimation functions (in SI_Base, SI_classic, SI_Area and SI_Mass), two blowing-snow size distributions (mode A vs. B) and two different ratios of SSA formation per blowing-snow particle (in SI_Classic_AX10 and SI_Classic_BX20) (see Table 1 for details). Panel (b) shows model sensitivity to snow salinity. SI_Base_A_SN is the same as the control run (SI_Base_A), apart from removing samples with salinity $>10$ psu. SI_Base_A_SL applies a fixed low salinity of $0.06 \mathrm{psu}$, and SI_Base_A_SH applies a high value of $0.92 \mathrm{psu}$. Vertical lines represent a diameter of 1 and $10 \mu \mathrm{m}$.

data ratio of aerosol number density in the sea ice zone reduces from the control run 2.76 to 1.8 in the SI_Base_A_R1 and 1.1 in the SI_Base_A_R2 (Table 2). As a result, the time series correlation coefficients between the model and the observations increase from $r=0.56$ in the control run $(\mathrm{OO}+$ SI_Base_A $)$ to 0.64 in both $\mathrm{OO}+\mathrm{SI}$-Base_A_R1 and OO + SI_Base_A_R2 runs (Table 2).

The blowing-snow-particle size distribution function also affects the SSA size distribution. A smaller $\alpha$ means there are more small snow particles (e.g. $<$ tens of microns) in the distribution than a larger $\alpha$. Thus, model runs with mode A $(\alpha=2)$ implemented normally produce more submicronsized SSA than with mode B ( $\alpha=3)$, as shown in Fig. 5a.

When a SSA production ratio greater than 1 is applied, the size of the dry $\mathrm{NaCl}$ formed will be reduced (refer to 
Eq. 11). Thus, at $N>1$, the SSA spectrum will shift towards smaller size bins. Figure 5a shows that, at size ranges of $>0.4 \mu \mathrm{m}$, Classic_AX10 and SI_Classic_BX20 give a very similar result to the SI_Base_A run, although with significant differences in smaller size bins (reflecting shape value effects, i.e. $\alpha=2$ in mode A vs. $\alpha=3$ in mode B). Salinity not only affects salt mass loading, but also the size distribution of SSA generated. As mentioned before, highly saline snow samples (e.g. with salinity $\geq 10 \mathrm{psu}$ ) only account for a small fraction of measurements (e.g. $\sim 4 \%$ of the Weddell Sea measurements). The model run (SI_Base_A_SN) without these saline snow samples shows a reduction of SSA concentration by $>50 \%$ at SSA size of $\sim 10 \mu \mathrm{m}$ and $\sim 20 \%$ at submicron-size mode (Fig. 5b). Given that large aerosols dominate the salt mass budget, high-salinity snow samples are important regarding the total amount of mass loading and chemical compound release (such as bromine) in the boundary layer. In a run (SI_Base_A_SL) with a fixed low snow salinity of $0.06 \mathrm{psu}$ (close to median salinity), a $>90 \%$ reduction in SSA number density at a size of $\sim 10 \mu \mathrm{m}$ (compared to the control run) is seen, with $\sim 20 \%$ reduction at a size of $<0.1 \mu \mathrm{m}$. On the contrary, in a run (SI_Base_A_SH) with a fixed high salinity of $0.92 \mathrm{psu}$ (close to mean salinity), an increase of $\sim 100 \%$ in submicron SSA (compared to the control run) is seen. The above experiments indicate that snow salinity is an important factor in determining both SSA mass loading and size distribution. Geographically, the difference in snow salinity on sea ice is expected to be large. For example, large differences can be expected between the Northern Hemisphere vs. Southern Hemisphere, young sea ice vs. multi-year sea ice, marginal sea ice vs. packed sea ice, etc. Even in the same geographic location, there could be seasonal evolution of snow salinity in association with for example salt loading and precipitation dilution. Currently we do not have a systematic measurement of snow salinity globally, which significantly impedes modelling efforts to simulate the realistic representation of SSA and bromine chemistry (e.g. Huang and Jaeglé, 2017; Rhodes et al., 2017; Legrand et al., 2017).

\subsection{Global scale}

Global model studies show that the observed winter SSA mass peaks at most polar sites can only be reproduced when the sea-ice-sourced SSAs are implemented (Levine et al., 2014; Huang and Jaeglé, 2017; Rhodes et al., 2017). Figure 6 shows an updated p-TOMCAT result of seasonal $\mathrm{Na}$ concentrations at eight polar stations (based on a 3-year integration, 2013-2015), which reinforces the importance of seaice-sourced SSA in reproducing the winter peaks of sodium observed, as sea spray (solid green lines) simply cannot do alone. As shown in Fig. 6, the model run SI_Classic_BX20 (solid yellow lines) gives a slightly higher $\mathrm{Na}$ mass concentrations than the control run SI_Base_A (red lines); this is due to the reduction of SSA size, e.g. by a factor of 2.7 when
$N=20$ is applied. The model run SI_Base_A_R1 (solid purple lines, with a fixed $\mathrm{RH}=90 \%$ ) gives slightly reduced SSA mass concentrations compared to SI_Base_A but still shows a clear winter SSA mass peak in most polar sites. However, SSA mass in SI_Base_A_R2 (dotted purple lines, with a fixed $\mathrm{RH}=95 \%$ ) is much suppressed and cannot represent the observations. Among all the sea-ice-sourced schemes, SI_Classic_A (dotted green lines) gives the least SSA mass and could not explain the winter peaks, which is due to the least submicron-sized SSA being formed in SI_Classic_A.

The three model runs (SI_Base_A, SI_Classic_AX10 and SI_Classic_BX20) give very similar mass loading (Fig. 6) and number density at a size of $>0.4 \mu \mathrm{m}$; however, they are quite different in terms of number density at smaller size bins, especially in ultra-fine mode (Fig. 5a). Figure 7 shows a zonal mean SSA number density from 1-year integration (2013) from these three runs. It can be seen that SI_Base_A has the largest SSA number production, with SSA number density over sea ice higher than that of sea spray in the marine boundary layer (Fig. 7a and d). On the contrary, SI_Classic_AX10 and SI_Classic_BX20 give much lower SSA number density with a maximum boundary layer density of $\sim 5$ and $\sim 3$ particles per cubic centimetre, respectively, which is still higher than the simulated sea spray contribution in the winter season in polar regions.

With detailed blowing-snow data, the shape parameter as well as the scale parameter can be well constrained, and then the larger differences in predicted SSA number density in submicron mode among these model runs (mainly between SI_Base_A and SI_Classic_AX10 or SI_Classic_BX20) can be used as indicators for validation, when aerosol data in ultra-fine mode becomes available from SIZ locations.

Overall, the control run SI_Base_A overestimates SSA number density (as shown in Fig. 1a) and underestimates mass concentration at sites such as Alert, Barrow and Neumayer (Fig. 6), indicating that the current model setups and parameterizations applied need further constraints and evaluation against data. Model runs with a fixed $\mathrm{RH}=90 \%$ (in SI_Base_A_R2) seem to outperform the control run SI_Base_A, indicating that the model moisture field, which determines the sublimation flux calculation, is a crucial factor that may greatly affect simulations. In addition, inclusion of drifting snow (which is missed by the model) as a source of SSA may improve SSA mass simulation in polar regions but will increase number density as well; thus this still will not reconcile the discrepancy between the model (the control run) and the observations in both number density and mass concentration. As discussed previously, apart from the sublimation rate applied, the blowing-snow size distribution (shape parameter $\alpha$ and scale parameter beta $\beta$ ) can also affect the SSA size spectrum, as shown in Fig. 5a (e.g. SI_Base_A vs. SI_Base_B). Cruise data show that the blowing-snow-particle size distribution varies as a function of height above the surface and wind speed (see details in Frey et al., 2019). Therefore it is important to apply a more 

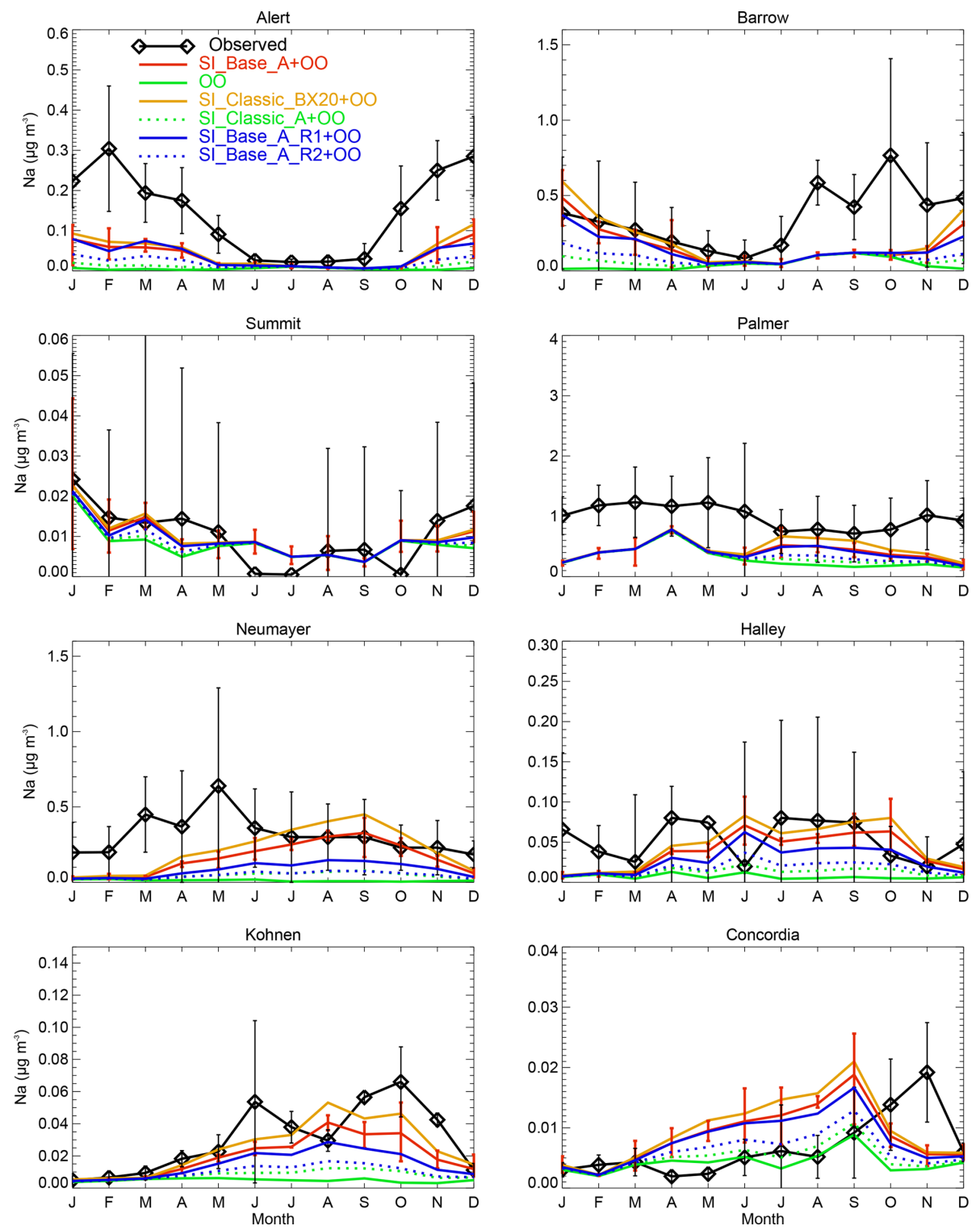

Figure 6. Monthly mean Na mass concentration at eight polar sites. Observations are shown in black with diamond symbols, with the uncertainty bars representing $\pm 1 \sigma$ of the inter-annual variability of the observation. Sea-spray-derived SSA is shown by the green line (from the open-ocean control run OO). Sea-ice-sourced SSA (together with sea spray) from SI_Base_A is shown by the red line with uncertainty bars representing the minimum and maximum of a 3-year integration (2013-2015). Monthly mean [Na] from the SI_Classic_BX20 run is shown in orange lines, the SI_Base_A_R1 run is shown in purple lines, the SI_Base_A_R2 run is shown in dashed purple lines, and the SI_Classic_A run is shown in dashed green lines. The mass concentration for model NaCl is at a diameter of $0.02-10 \mu \mathrm{m}$. The aerosol data are from the following sources: the Alert, Barrow and Palmer data are from the AEROCE-SEAREX network (Savoie et al., 2002); the Neumayer data are from Weller et al. (2011); the Halley data are from Rankin et al. (2004); the Kohnen data are from Weller and Wagenbach (2007); the Concordia data are from Legrand et al. (2016); and the Summit data are from Mosher et al. (1993) but following Rhodes et al. (2017).

realistic blowing-snow distribution to constrain this key parameter; we plan to investigate this issue by applying a time series of observed blowing-snow size distribution along the cruise track to further constrain this parameter to narrow down the uncertainty.

\section{Possible physical mechanisms involved in the SSA production from blowing snow}

As discussed in Sect. 3.3.1, under the assumption that one snow particle only forms one SSA after sublimation, the SI_Mass_A run shows the least correspondence to the cruise observations, by several orders of magnitude 

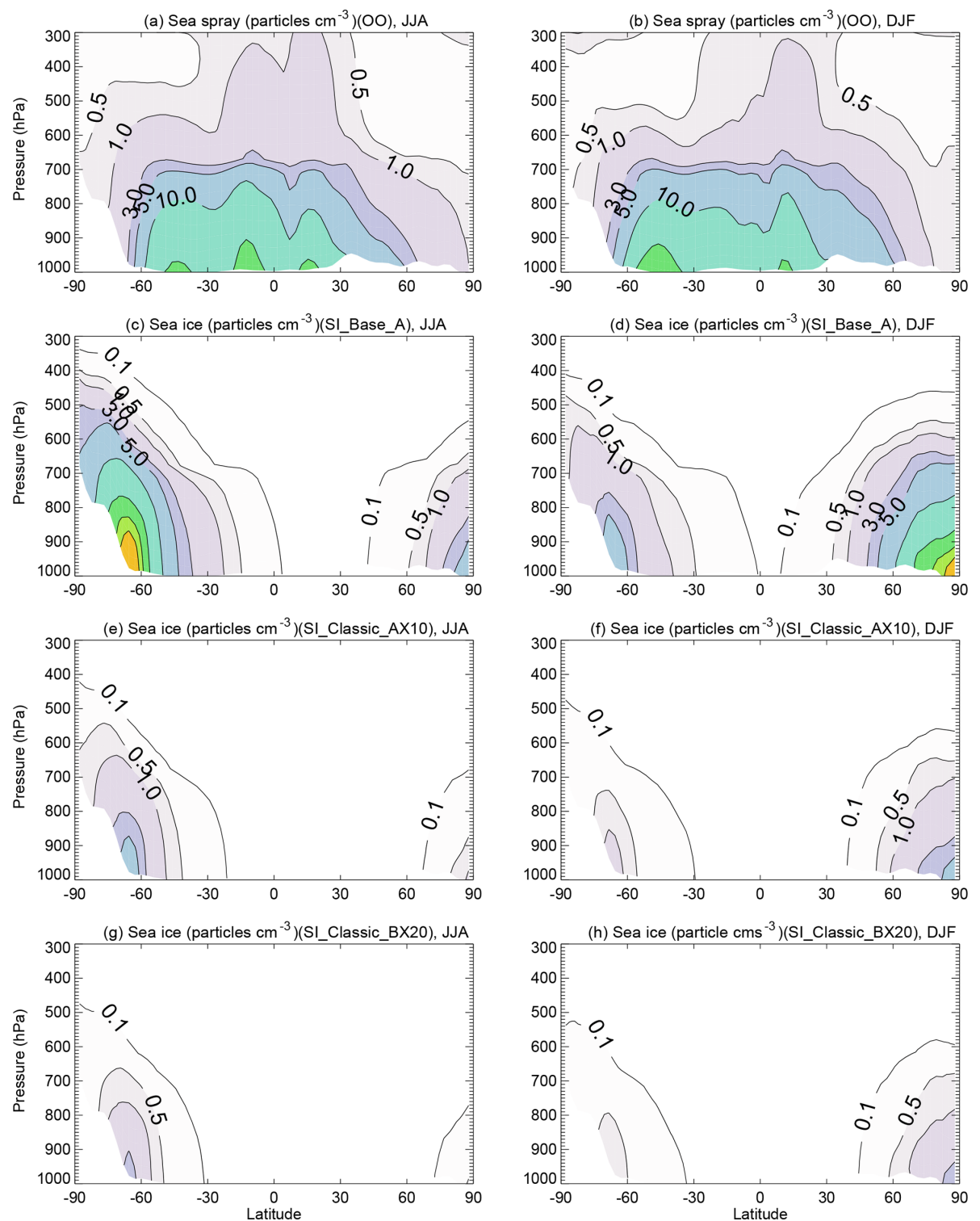

Figure 7. Zonal mean SSA total number concentration (particles $\mathrm{cm}^{-3}$ ) from the sea spray open ocean in (a) June-July-August (JJA) and (b) December-January-February (DJF) from the OO run. Sea-ice-sourced SSA from the SI_Base_A run shown in (c) and (d), with the SI_Classic_AX10 run result in (e) and (f) and the SI_Classic_BX20 run result in (g) and (h). The plots are based on 1-year (2013) integration. The contour interval is 10 particles $\mathrm{cm}^{-3}$ when number density is larger than 10 particles $\mathrm{cm}^{-3}$.

(Fig. 5a). Thus, it is safe to rule out the physical mechanism represented by the sublimation function implemented, which assumes that the SSA should come from an unsorted sample of suspended wind-blown-snow particles in the blowing-snow layer that lose their water completely without any replenishment from newly generated snow particles. SI_Classic_A and SI_Classic_B runs agree better than SI_Area_A and SI_Mass_A runs but still cannot generate enough submicron-size SSAs to match the observations. SI_Base_A and SI_Base_B are, instead, much closer to the observations with mode-data ratios ranging within 0.8-2.8 (Table 2). As discussed previously, SI_Base runs claim a particle sublimation function of $\frac{\mathrm{d} m_{\mathrm{i}}}{\mathrm{d} t} \propto$ constant or $\frac{\mathrm{d} r}{\mathrm{~d} t} \propto \frac{1}{r^{2}}$, demanding the water loss is dominated by the curvature effect and/or the so-called air ventilation effect. Instead, the SI_Classic run applies a well-known function of $\frac{\mathrm{d} r}{\mathrm{~d} t} \propto \frac{1}{r}$, indicating the water loss is controlled by the moisture gradient (diffusion effect) for a snow particle in subsaturated air.

There is a possibility that more than one SSA could be formed from one saline snow particle. If this is the case, then the discrepancies between SI_Classic_A (or SI_Classic_B) and the observations could be reduced. For example, when a SSA production ratio of 10 per snow particle is applied to SI_Classic_A (denoted as SI_Classic_AX10), or a ratio 
of 20 to SI_Classic_B (denoted as SI_Classic_BX20), then a result similar to the control run (SI_Base_A) in a particle size of $\sim 0.4-12 \mu \mathrm{m}$ can be obtained (Figs. 1e or 5a). For SI_Area_A a ratio of $N=\sim 100$ is needed, with an even larger ratio needed for SI_Mass_A, to match the observations (not shown). However, the current cruise data will not allow us to separate or pinpoint which process is more plausible, demanding further investigation on this issue.

Cruise data show that the blowing-snow-particle number densities decrease significantly, e.g. by more than an order of magnitude from the near surface $(\sim 2 \mathrm{~m}$ above snow surface) to $\sim 29 \mathrm{~m}$. However, aerosol number densities between these two levels do not show such a large gradient as observed for blowing snow. For example, observed data indicate (see Fig. 5 in Frey et al., 2019) that during drifting snow episodes aerosol number densities increased significantly, especially those of submicron-sized particles at both measurement heights, with a lightly greater increase near the surface (number density up to $10^{7} \mathrm{~m}^{-3}$ for diameter $<2 \mu \mathrm{m}$ ). During blowing snow, number densities showed similar increases as during drifting snow; however, at $29 \mathrm{~m}$ concentrations were higher and particles were larger (at a diameter of $>9 \mu \mathrm{m}$ ) than at $2 \mathrm{~m}$. This observational evidence will not allow us to derive any robust conclusion regarding where SSA is generated: in the near-surface layer where RH is saturated or at the top of the blowing-snow layer where RH is likely under saturated. If SSA is mainly produced near the surface layer, then snow particle sublimation will be controlled by the curvature effect (following the SI_Base mechanism). However, if SSA is produced in the subsaturated condition, e.g. at the top layer or above the blowing-snow layer, then water sublimation will follow the SI_Classic mechanism.

Model experiments with the above two mechanisms implemented (e.g. SI_Base_A and SI_Classic_AX10) can produce roughly the same number density at a size range of $\sim 0.4-12 \mu \mathrm{m}$. However, at an SSA diameter size of $<0.4 \mu \mathrm{m}$, their results are quite different as shown in Figs. $4 \mathrm{c}$ and $5 \mathrm{a}$. For example, at a diameter of $0.1 \mu \mathrm{m}$, SI_Base_A has a mean SSA number density almost an order of magnitude larger than that of SI_Classic_AX10 (and SI_Classic_BX20). Therefore, a precise observation of SSA at submicron-size mode can help to diagnose which microphysical mechanism(s) dominates the SSA production. A systematic measurement of the size-segregated chemical composition of SSA over a size range of 0.03 to $20 \mu \mathrm{m}$ diameter, together with a complete spectrum of blowing-snowparticle size, will help to distinguish which mechanism dominates SSA production from blowing snow.

To highlight the above-mentioned SSA production mechanisms and make a direct comparison with the sea spray flux, a theoretical calculation is performed with results shown in Fig. 8. The bulk sublimation flux is calculated under polar weather conditions of wind speed equal to $12 \mathrm{~m} \mathrm{~s}^{-1}$, temperature equal to $-10{ }^{\circ} \mathrm{C}$ and $\mathrm{RH}$ (with respect to ice) equal to $80 \%$, with a zero snow age and a constant snow salin- ity of 0.06 psu. It can be seen from Fig. 8a that SI_Base_Aa allocates most water, higher than SI_Classic_Aa, to small snow particles at a diameter of $<$ tens of microns, while both SI_Area_Aa and SI_Mass_Aa allocate little water to these snow size bins. As a consequence, they have the smallest SSA production rate at submicron-size mode and highest rate at micron-size mode (Fig. 8c, d).

At sub- to micron-size mode, SI_Classic_Aa shows a comparable flux to sea spray calculated at the same wind speed following the Jaegle et al. (2011) scheme with a $\mathrm{SST}=5^{\circ} \mathrm{C}$ (dotted black line in Fig. 8) and the Caffrey et al. (2006) scheme (solid black line). SI_Base_Aa and SI_Classic_AaX10 both show a stronger SSA production flux at sizes of less than a few microns. At an SSA diameter of $0.1-1 \mu \mathrm{m}$, they both show a flux of $>10$ times that of sea spray (by OO_Jaeglé); at ultra-fine mode $(<0.1 \mu \mathrm{m})$, SI_Base_A has a production flux larger than the OO_Jaeglé flux by $>2$ orders of magnitude.

Apart from a nearly 10 times increase in the number density, compared to Classic_Aa, Classic_AaX10 also shows a shift in the SSA size spectrum towards smaller bins with a roughly halved $\mathrm{NaCl}$ size according to Eq. (11), indicating that more smaller SSAs formed, as shown in Fig. 8d. Figure 8e shows that SI_Base_Aa and SI_Classic_AaX10 have the largest submicron SSA accumulation fraction, accounting for $\sim 2 \%$ of the total mass, which is $>10$ times the sea spray fraction. This enhanced submicron-size partitioning from the sea ice surface may contribute to the observed enhancement of submicron-size SSA in polar winter (e.g. Rankin and Wolff et al., 2003; Quinn et al., 2002). Figure 8d also shows that at a large SSA size, e.g. $>10 \mu \mathrm{m}$, blowing snow generates fewer SSAs than sea spray, strongly indicating that sea spray and sea-ice-sourced SSA have quite different fingerprints.

The assumption that one blowing-snow particle only forms one SSA after sublimation means, at steady state, that the SSA number production rate should be the same as the snow particle loss rate and the replenishment rate of newly formed snow particles. For that reason, Eq. (2) can be used to describe the blowing-snow-particle production flux (in vertical dimension) due to the sublimation effect (Fig. 8b). However, our cruise data will not allow us to validate this flux and derive any robust conclusion.

\section{Conclusion}

The Weddell Sea cruise data give us a unique opportunity to constrain some key parameters involved in SSA production, validate parameterizations and investigate possible microphysical processes involved. Unfortunately, due to a lack of data at smaller particle sizes, e.g. $<0.4 \mu \mathrm{m}$, we could not pinpoint the exact mechanism that is responsible for SSA production from blowing snow. However, the current data and model integrations suggest two plausible mechanisms. 

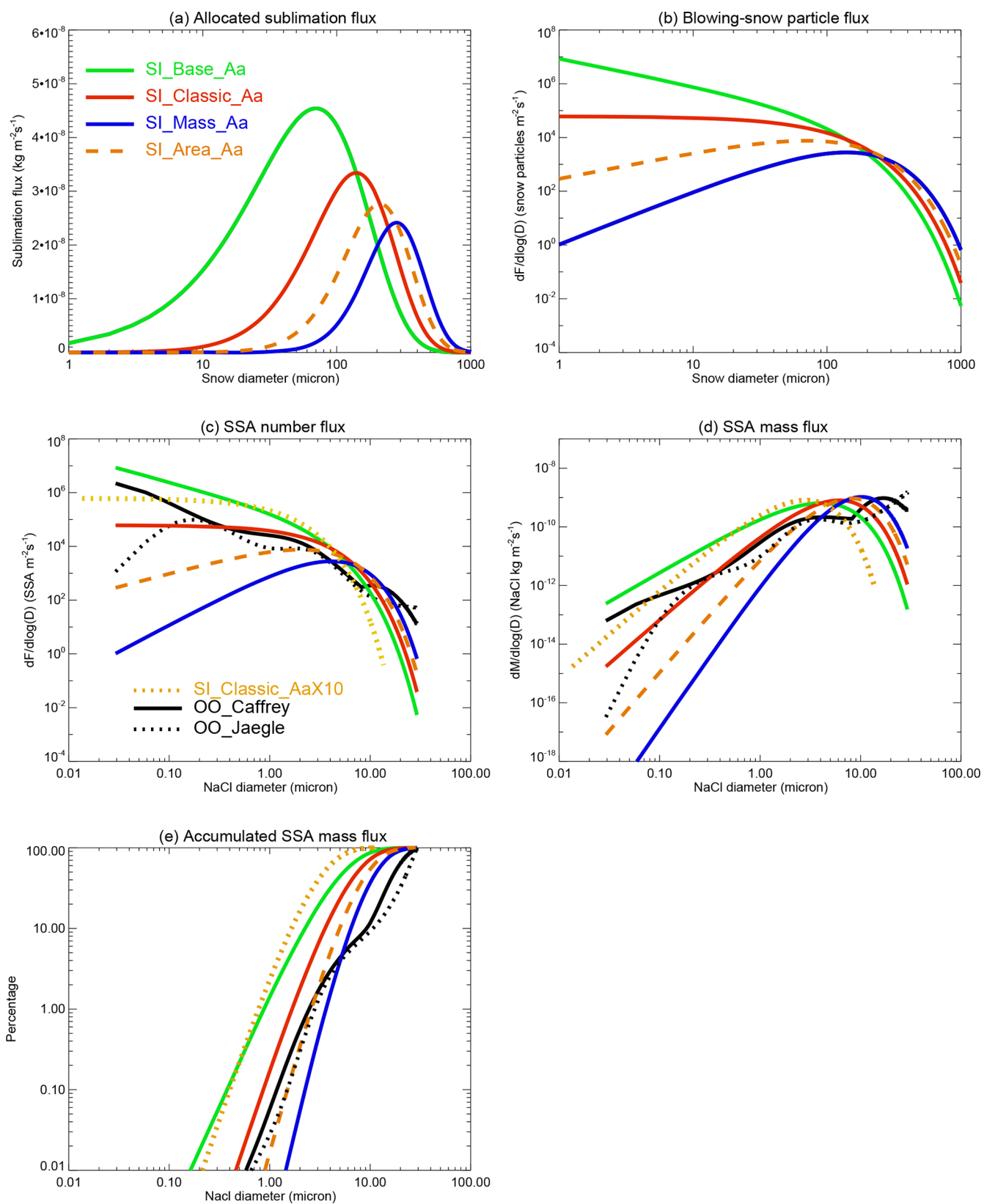

Figure 8. (a) Allocated sublimation fluxes across different snow size bins (with a bin interval of $1 \mu \mathrm{m}$ ) in each experiment. Note that the bulk sublimation flux used for allocation is calculated under conditions of wind speed $=12 \mathrm{~m} \mathrm{~s}^{-1}$, temperature $=-10^{\circ} \mathrm{C}, \mathrm{RH}$ (with respect to ice) $=80 \%$ and snow age $=0 \mathrm{~d}$. (b) Converted blowing-snow-particle production flux. (c) Corresponding SSA number production flux. Note that the conversion is under a fixed snow salinity of $0.06 \mathrm{psu}$ and assuming one SSA from one saline blown-snow particle. Two open-ocean sea spray fluxes under the same wind speed of $12 \mathrm{~m} \mathrm{~s}^{-1}$ (SST $=5^{\circ} \mathrm{C}$ for OO_Jaeglé) are shown for comparison. (d) Same as (c) apart from for the mass flux. (e) Accumulated mass flux percentages.

The first one is under an assumption that only one SSA is formed per snow particle. Under this assumption, to match the observations (with size ranging from 0.4 to $12 \mu \mathrm{m}$ ), it demands that the curvature effect dominates water sublimation (as proposed in Yang et al., 2008). This mechanism implies that SSA should be generated under a saturated environment, e.g. near the surface layer, rather than in a layer on top of the blowing-snow layer where subsaturation is likely. The second mechanism allows for more than one SSA formed per snow particle, due to the breaking-up effect. To match the observations, it demands a ratio of 10 SSA per snow particle for SI_Classic_A and a ratio of 20 for SI_Classic_B. This mechanism is built on the microphysical process in which snow sublimation rate is dominated by the moisture gradi- 
ent between the snow surface and the ambient air (or the moisture diffusion effect). Although the ratio value needed (to match the observations) varies among different model setups (e.g. the total sublimation flux and blowing-snow size distribution), it clearly demands that SSA should be produced in a subsaturated layer, e.g. on top of the blowing-snow layer, rather than inside of the blowing-snow layer. However, the aerosol concentration gradient observed between the near surface ( $\sim 2 \mathrm{~m}$ above snow surface) and $\sim 29 \mathrm{~m}$ will not allow us to conclude robustly where the SSA is produced. In addition, the large biases in the converted $\mathrm{RH}$ (with respect to ice) (Frey et al., 2019) at the two heights also prevent us from pinpointing which process is underlying the SSA production. Also, there is little knowledge regarding the air ventilation effect on the crystal particle sublimation process, which may accelerate the water vapour sublimation rate from all sizes of snow particles and under both saturated and subsaturated conditions. Thus, this highlights the need for further in situ observations, laboratory investigation and modelling to fill this gap. Climate models are then critically needed to estimate the impact of this newly identified sea-ice-sourced SSA on local and regional climate, directly (via scattering sunlight) and indirectly (by acting as cloud condensation nuclei, influencing cloud and precipitation).

Data availability. All data used in plotting are stored in the UK Polar Data Centre, Natural Environment Research Council, UK Research and Innovation (https://doi.org/10.5285/8838b0b7-20b746bb-8cf1-b853290b2035, Yang et al., 2019).

Author contributions. EWW, MMF, AEJ and PSA designed the field experiment; MMF carried out the field measurements. XY designed and performed model experiments and interpreted the model output and the microphysical mechanisms proposed. RHR contributed to model development, SJN and IMB to CLASP, and KN to SPC instruments. XY prepared the manuscript with contributions from all co-authors.

Competing interests. The authors declare that they have no conflict of interest.

Acknowledgements. We thank the Alfred Wegener Institute for Polar and Marine Research, which made our participation in the cruise possible. We gratefully acknowledge financial support from the Natural Environment Research (NERC) in the UK through the project BLOWSEA. Rachael H. Rhodes was supported by a European Commission Horizon 2020 Marie Sklodowska-Curie Individual Fellowship. Eric W. Wolff is supported by a Royal Society Professorship. Xin Yang thanks Wuhu Feng and Martyn Chipperfield for support in using ERA-Interim data. Thanks also go to Stephen P. Palm for useful discussions.
Financial support. This research has been supported by the Natural Environment Research (NERC) in the UK (grant nos. NE/J023051/1 and NE/J020303/1), the European Commission Horizon 2020 Marie Sklodowska-Curie Individual Fellowship (SEADOG (grant no. 658120)) and the Royal Society Professorship (grant nos. RP120096 and RP/R/180003).

Review statement. This paper was edited by Christopher Hoyle and reviewed by two anonymous referees.

\section{References}

Abram, N. J., Wolff, E. W., and Curran, M. A. J.: A review of sea ice proxy information from polar ice cores, Quaternary Sci. Rev., 79, 168-183, https://doi.org/10.1016/j.quascirev.2013.01.011, 2013.

Butler, B. M., Papadimitriou, S., Santoro, A., and Kennedy, H.: Mirabilite solubility in equilibrium sea ice brines, Geochim. Cosmochim. Ac., 182, 40-54, https://doi.org/10.1016/j.gca.2016.03.008, 2016.

Box, J. E., Bromwich, D. H., and Bai, L.-S.: Greenland ice sheet surface mass balance 1991-2000: Application of Polar MM5 mesoscale model and in situ data, J. Geophys. Res., 109, D16105, https://doi.org/10.1029/2003JD004451, 2004.

Caffrey, P. F., Hoppel, W. A., and Shi, J. J.: A one-dimensional sectional aerosol model integrated with mesoscale meteorological data to study marine boundary layer aerosol dynamics, J. Geophys. Res., 111, D24201, https://doi.org/10.1029/2006jd007237, 2006.

Caughey, S. J., Wyngaard, J. C., and Kaimal, J. C.: Turbulence in the evolving stable boundary layer, J. Atmos. Sci., 36, 1041-1052, 1979.

Choi, S., Theys, N., Salawitch, R. J., Wales, P. A., Joiner, J., Canty, T. P., Chance, K., Suleiman, R. M., Palm, S. P., Cullather, R. I., darmenov, A. S., da Silva, A., Kurosu, T. P., Hendrick, F., and Van Roozendael, M.: Link between Arctic tropospheric BrO explosion observed from space and sea-salt aerosols from blowing snow investigated using Ozone Monitoring Instrument $\mathrm{BrO}$ data and GEOS-5 data assimilation system, J. Geophys. Res., 123, 6954-6983, https://doi.org/10.1029/2017JD026889, 2018.

Clifton, A., Ruedi, J. D., and Lehning, M.: Snow saltation threshold measurements in a drifting-snow wind tunnel, J. Glaciol., 52, 585-596, https://doi.org/10.3189/172756506781828430, 2006.

de Leeuw, G., Andreas, E. L., Anguelova, M. D., Fairall, C. W., Lewis, E. R., O'Dowd, C., Schulz, M., and Schwartz, S. E.: Production flux of sea spray aerosol, Rev. Geophys., 49, RG2001, https://doi.org/10.1029/2010RG000349, 2011.

DeMott, P. J., Hill, T. C. J., McCluskey, C. S., Prather, K. A., Collins, D. B., Sullivan, R. C., Ruppel, M. J., Mason, R. H., Irish, V. E., Lee, T., Hwang, C. Y., Rhee, T. S., Snider, J. R., McMeeking, G. R., Dhaniyala, S., Lewis, E. R., Wentzell, J. J. B., Abbatt, J., Lee, C., Sultana, C. M., Ault, A. P., Axson, J. L., Diaz Martinez, M., Venero, I., Santos-Figueroa, G., Stokes, M. D., Deane, G. B., Mayol-Bracero, O. L., Grassian, V. H., Bertram, T. H., Bertram, A. K., Moffett, B. F., and Franc, G. D.: Sea spray aerosol as a unique source of ice nucleating particles, P. Natl. Acad. Sci. USA, 113, 5797-5803, https://doi.org/10.1073/pnas.1514034112, 2015. 
Déry, S. J. and Yau, M. K.: A bulk blowing snow model, Bound.Lay. Meteorol., 93, 237-251, 1999.

Déry, S. J. and Yau, M. K.: Simulation of blowing snow in the Canadian Arctic using a double-moment model, Bound.-Lay. Meteorol., 99, 297-316, 2001.

Dick, A. L.: A simple model for air/snow fractionation of aerosol components over the Antarctic Peninsula, J. Atmos. Chem., 11, 179-196, 1990.

Dover, S. E.: Numerical modelling of blowing snow, $\mathrm{PhD}$ thesis, 237 pp., Dep. of App. Math., Univ. of Leeds, Leeds, UK, 1993.

Doorschot, J. J., Lehning, M., and Vrouwe, A.: Field measurements of snow-drift threshold and mass fluxes, and related model simulations, Bound.-Lay. Meteorol., 113, 347-368, 2004.

Frey, M. M., Norris, S. J., Brooks, I. M., Anderson, P. S., Nishimura, K., Yang, X., Jones, A. E., Nerentorp Mastromonaco, M. G., Jones, D. H., and Wolff, E. W.: First direct observation of sea salt aerosol production from blowing snow above sea ice, Atmos. Chem. Phys. Discuss., https://doi.org/10.5194/acp-2019-259, in review, 2019.

Hara, K., Matoba, S., Hirabayashi, M., and Yamasaki, T.: Frost flowers and sea-salt aerosols over seasonal sea-ice areas in northwestern Greenland during winter-spring, Atmos. Chem. Phys., 17, 8577-8598, https://doi.org/10.5194/acp-178577-2017, 2017.

Hill, M. K., Brooks, B. J., Norris, S. J., Smith, M. H., Brooks, I. M., and de Leeuw, G.: A Compact Lightweight Aerosol Spectrometer Probe (CLASP), J. Atmos. Ocean. Tech., 25, 1996-2006, https://doi.org/10.1175/2008JTECHA1051.1, 2008.

Houghton, H. G.: A study of the evaporation of small water drops, Physics, 4, 419-424, 1933.

Huang, J. and Jaeglé, L.: Wintertime enhancements of sea salt aerosol in polar regions consistent with a sea ice source from blowing snow, Atmos. Chem. Phys., 17, 3699-3712, https://doi.org/10.5194/acp-17-3699-2017, 2017.

Jaeglé, L., Quinn, P. K., Bates, T. S., Alexander, B., and Lin, J.-T.: Global distribution of sea salt aerosols: new constraints from in situ and remote sensing observations, Atmos. Chem. Phys., 11, 3137-3157, https://doi.org/10.5194/acp-11-3137-2011, 2011.

Jourdain, B., Preunkert, S., Cerri, O., Castebrunet, H., Udisti, R., and Legrand, M.: Year-round record of size-segregated aerosol composition in central Antarctica (Concordia station): Implications for the degree of fractionation of sea-salt particles, J. Geophys. Res., 113, D14308, https://doi.org/10.1029/2007jd009584, 2008 .

Kaleschke, L., Richter, A., Burrows, J., Afe, O., Heygster, G., Notholt, J., Rankin, A. M., Roscoe, H. K., Hollwedel, J., Wagner, T., and Jacobi, H.-W.: Frost flowers on sea ice as a source of sea salt and their influence on tropospheric halogen chemistry, Geophys. Res. Lett., 31, L16114, https://doi.org/10.1029/2004GL020655, 2004.

King, J. C. and Turner, J.: Antarctic Meteorology and Climatology, Cambridge University Press, 302 pp., 1997.

Legrand, M., Yang, X., Preunkert, S., and Theys, N.: Year-round records of sea salt, gaseous, and particulate inorganic bromine in the atmospheric boundary layer at coastal (Dumont d'Urville) and central (Concordia) East Antarctic sites, J. Geophys. Res.Atmos., 121, 997-1023, https://doi.org/10.1002/2015JD024066, 2016
Legrand, M., Preunkert, S., Wolff, E., Weller, R., Jourdain, B., and Wagenbach, D.: Year-round records of bulk and sizesegregated aerosol composition in central Antarctica (Concordia site) - Part 1: Fractionation of sea-salt particles, Atmos. Chem. Phys., 17, 14039-14054, https://doi.org/10.5194/acp-17-140392017, 2017.

Levine, J. G., Yang, X., Jones, A. E., and Wolff, E. W.: Sea salt as an ice core proxy for past sea ice extent: A processbased model study, J. Geophys. Res.-Atmos., 119, 5737-5756, https://doi.org/10.1002/2013JD020925, 2014

Li, L. and Pomeroy, J. W.: Probability of blowing snow occurrence by wind, J. Geophys. Res., 102, 21955-21964, 1997.

Male, D. H.: Dynamics of snow and ice masses, edited by: Colbeck, S. C., 323 pp., Academic Press, Cambridge, Massachusetts, USA, 1980.

Mann, G. W., Anderson, P. S., and Mobbs, S. D.: Profile measurements of blowing snow at Halley, Antarctica, J. Geophys. Res. 105, 24491-24508, 2000.

Mason, B. J.: The Physics of Clouds, Clarendon Press, Oxford, 671 pp., 1971.

Mosher, B. W., Winkler, P., and Jaffrezo, J.-L.: Seasonal aerosol chemistry at Dye 3, Greenland, Atmos. Environ. A-Gen., 27, 2761-2772, 1993.

Murphy, D. M., Anderson, J. R., Quinn, P. K., Mclnnes, L. M., Posfai, M., Thomson, D. S., and Buseck, P. R.: Influence of seasalt on aerosol radiative properties in the Southern Ocean marine boundary layer, Nature, 392, 62-65, 1998.

Nemoto, M. and Nishimura, K.: Numerical simulation of snow saltation and suspension in a turbulent boundary layer, J. Geophys. Res., 109, D18206, https://doi.org/10.1029/2004JD004657, 2004.

Nerentorp Mastromonaco, M., Gårdfeldt, K., Jourdain, B., Abrahamsson, K., Granfors, A., Ahnoff, M., Dommergue, A., Méjean, G., and Jacobi, H.-W.: Antarctic winter mercury and ozone depletion events over sea ice, Atmos. Environ., 129, 125-132, 2016.

Nishimura, K. and Nemoto, M.: Blowing snow at Mizuho station, Antarctica, Philos. T. R. Soc. A, 363, 1647-1662, https://doi.org/10.1098/rsta.2005.1599, 2005.

Nishimura, K., Yokoyama, C., Ito, Y., Nemoto, M., NaaimBouvet, F., Bellot, H., and Fujita, K.: Snow particle speeds in drifting snow, J. Geophys. Res.-Atmos., 119, 9901-9913, https://doi.org/10.1002/2014JD021686, 2014.

Norris, S. J., Brooks, I. M., de Leeuw, G., Smith, M. H., Moerman, M., and Lingard, J. J. N.: Eddy covariance measurements of sea spray particles over the Atlantic Ocean, Atmos. Chem. Phys., 8, 555-563, https://doi.org/10.5194/acp-8-555-2008, 2008.

Obbard, R. W., Roscoe, H. K., Wolff, E. W., and Atkinson, H. M.: Frost ower surface area and chemistry as a function of salinity and temperature, J. Geophys. Res., 114, D20305, https://doi.org/10.1029/2009JD012481, 2009.

O'Dowd, C. D. and Smith, M. H.: Physicochemical properties of aerosols over the northeast Atlantic: Evidence for wind-speedrelated submicron sea-salt aerosol production, J. Geophys. Res., 98, 1137-1149, 1993.

O’Dowd, C. D., Smith, M. H., Consterdine, I. E., and Lowe, J. A.: Marine aerosol, sea salt, and the marine sulphur cycle: A short review, Atmos. Environ., 31, 73-80, 1997. 
O’Dowd, C. D., Lowe, J., Smith, M. H., and Kaye, A. D.: The relative importance of sea-salt and nss-sulphate aerosol to the marine CCN population: An improved multi-component aerosol-droplet parameterisation, Q. J. Roy. Meteor. Soc., 125, 1295-1313, 1999.

Pomeroy, J. W., Gray, D. M., and Landine, P. G.: The prairie blowing snow model: characteristics, validation, operation, J. Hydrol., 144, 165-192, 1993.

Pruppacher, H. R. and Klett, J. D.: Microphysics of Clouds and Precipitation, Kluwer Acad., Norwell, Mass., 1997.

Quinn, P. K., Miller, T. L., Bates, T. S., Ogren, J. A., Andrews, E., and Shaw, G. E.: A 3-year record of simultaneously measured aerosol chemical and optical properties at Barrow Alaska, J. Geophys. Res., 107, 4130, https://doi.org/10.1029/2001JD001248, 2002.

Rankin, A. M. and Wolff, E. W.: A year-long record of sizesegregated aerosol composition at Halley, Antarctica, J. Geophys. Res., 108, 4775, https://doi.org/10.1029/2003JD003993, 2003.

Rankin, A. M., Auld, V., and Wolff, E. W.: Frost flowers as a source of fractionated sea salt aerosol in the polar regions, Geophys. Res. Lett., 27, 3469-3472, 2000.

Rankin, A. M., Wolff, E. W., and Martin, S.: Frost flowers: Implications for tropospheric chemistry and ice core interpretation, J. Geophys. Res., 107, 4683, https://doi.org/10.1029/2002JD002492, 2002.

Rankin, A. M., Wolff, E. W., and Mulvaney, R.: A reinterpretation of sea-salt records in Greenland and Antarctic ice cores?, Ann. Glaciol., 39, 276-282, https://doi.org/10.3189/172756404781814681, 2004.

Rayner, N. A., Parker, D. E., Horton, E. B., Folland, C. K., Alexander, L. V., Rowell, D. P., Kent, E. C., and Kaplan, A.: Global analyses of sea surface temperature, sea ice, and night marine air temperature since the late nineteenth century, J. Geophys. Res., 108, 4407, https://doi.org/10.1029/2002JD002670, 2003.

Rhodes, R. H., Yang, X., Wolff, E. W., McConnell, J. R., and Frey, M. M.: Sea ice as a source of sea salt aerosol to Greenland ice cores: a model-based study, Atmos. Chem. Phys., 17, 94179433, https://doi.org/10.5194/acp-17-9417-2017, 2017.

Roscoe, H. K., Brooks, B., Jackson, A. V., Smith, M. H., Walker, S. J., Obbard, R. O., and Wolff, E. W.: Frost flowers in the laboratory: growth, characteristics, aerosol, and the underlying sea ice, J. Geophys. Res., 116, D12301, https://doi.org/10.1029/2010JD015144, 2011.

Savoie, D. L., Arimoto, R., Keene, W. C., Prospero, J. M., Duce, R. A., and Galloway, J. N.: Marine biogenic and anthropogenic contributions to non-sea-salt sulfate in the marine boundary layer over the North Atlantic Ocean, J. Geophys. Res.-Atmos., 107, 4356, https://doi.org/10.1029/2001JD000970, 2002.

Severi, M., Becagli, S., Caiazzo, L., Ciardini, V., Colizza, E., Giardi, F., Mezgec, K., Scarchilli, C., Stenni, B., Thomas, E. R., and Traversi, R.: Sea salt sodium record from Talos Dome (East Antarctica) as a potential proxy of the Antarctic past sea ice extent, Chemosphere, 177, 266-274, https://doi.org/10.1016/j.chemosphere.2017.03.025, 2017.

Schmidt, R. A.: Vertical profiles of wind speed, snow concentration, and humidity in blowing snow, Bound.-Lay. Meteorol., 23, 223246, 1982.

Theys, N., Van Roozendael, M., Hendrick, F., Yang, X., De Smedt, I., Richter, A., Begoin, M., Errera, Q., Johnston, P. V., Kreher, K., and De Mazière, M.: Global observations of tropospheric BrO columns using GOME-2 satellite data, Atmos. Chem. Phys., 11, 1791-1811, https://doi.org/10.5194/acp-11-1791-2011, 2011.

Thorp, A. D. and Mason, B. J.: The evaporation of ice spheres and ice crystals, Brit. J. Appl. Phys., 17, 541-548, 1967.

Wagenbach, D., Ducroz, F., Mulvaney, R., Keck, L., Minikin, A., Legrand, M., Hall, J. S., and Wolff, E. W.: Seasalt aerosol in coastal Antarctic regions, J. Geophys. Res., 103, 10961-10974, https://doi.org/10.1029/97JD01804, 1998.

Weller, R. and Wagenbach, D.: Year-round chemical aerosol records in continental Antarctica obtained by automatic samplings, Tellus B, 59, 755-765, 2007.

Weller, R., Wagenbach, D., Legrand, M., Elsässer, C., Tian-Kunze, X., and König-Langlo, G.: Continuous 25-years aerosol recordsat coastal Antarctica: 1. Inter-annual variability of ionic compounds and links to climate indices, Tellus B, 63, 044011, https://doi.org/10.1111/j.1600-0889.2011.00542.x, 2011.

Wise, M. E., Baustian, K. J., Koop, T., Freedman, M. A., Jensen, E. J., and Tolbert, M. A.: Depositional ice nucleation onto crystalline hydrated $\mathrm{NaCl}$ particles: a new mechanism for ice formation in the troposphere, Atmos. Chem. Phys., 12, 1121-1134, https://doi.org/10.5194/acp-12-1121-2012, 2012.

Wolff, E. W., Rankin, A. M., and Röthlisberger, R.: An ice core indicator of Antarctic sea ice production?, Geophys. Res. Lett., 30, 2158, https://doi.org/10.1029/2003GL018454, 2003.

Xu, L., Russell, L. M., and Burrows, S. M.: Potential sea salt aerosol sources from frost flowers in the panArctic region, J. Geophys. Res.-Atmos., 121, 10840-10856, https://doi.org/10.1002/2015JD024713, 2016.

Yang, X., Pyle, J. A., and Cox, R. A.: Sea salt aerosol production and bromine release: Role of snow on sea ice, Geophys. Res. Lett., 35, L16815, https://doi.org/10.1029/2008g1034536, 2008.

Yang, X., Pyle, J. A., Cox, R. A., Theys, N., and Van Roozendael, M.: Snow-sourced bromine and its implications for polar tropospheric ozone, Atmos. Chem. Phys., 10, 7763-7773, https://doi.org/10.5194/acp-10-7763-2010, 2010.

Yang, X., Neděla, V., Runštuk, J., Ondrušková, G., Krausko, J., Vetráková, L., and Heger, D.: Evaporating brine from frost flowers with electron microscopy and implications for atmospheric chemistry and sea-salt aerosol formation, Atmos. Chem. Phys., 17, 6291-6303, https://doi.org/10.5194/acp-176291-2017, 2017.

Yang, X., Pyle, J. A., and Cox, R. A.: Modelling and observed sea salt aerosol in the Weddell Sea (June-August 2013), UK Polar Data Centre; British Antarctic Survey, NERC, UKRI, https://doi.org/10.5285/8838b0b7-20b7-46bb8cf1-b853290b2035, 2019.

Zhao, X., Strong, K., Adams, C., Schofield, R., Yang, X., Richter, A., Friess, U., Blechschmidt, A.-M., and Koo, J.-H.: A case study of a transported bromine explosion event in the Canadian high arctic, J. Geophys. Res.-Atmos., 121, 457-477, https://doi.org/10.1002/2015JD023711, 2016.

Zhao, X., Weaver, D., Bognar, K., Manney, G., Millán, L., Yang, X., Eloranta, E., Schneider, M., and Strong, K.: Cyclone-induced surface ozone and HDO depletion in the Arctic, Atmos. Chem. Phys., 17, 14955-14974, https://doi.org/10.5194/acp-17-149552017, 2017. 